Florida International University FIU Digital Commons

\title{
The Effects of Resilience and Social Influences on Preventing Repeat Adolescent Pregnancies in Parenting Adolescent Mothers
}

Nola A. Holness

FIU, nholn001@fiu.edu

DOI: $10.25148 /$ etd.FI14040804

Follow this and additional works at: https:// digitalcommons.fiu.edu/etd

Part of the Maternal, Child Health and Neonatal Nursing Commons, and the Nursing Midwifery Commons

\section{Recommended Citation}

Holness, Nola A., "The Effects of Resilience and Social Influences on Preventing Repeat Adolescent Pregnancies in Parenting Adolescent Mothers" (2014). FIU Electronic Theses and Dissertations. 1120.

https://digitalcommons.fiu.edu/etd/1120 


\section{FLORIDA INTERNATIONAL UNIVERSITY}

Miami, Florida

\section{THE EFFECTS OF RESILIENCE AND SOCIAL INFLUENCES ON PREVENTING REPEAT ADOLESCENT PREGNANCIES IN PARENTING ADOLESCENT MOTHERS}

A dissertation submitted in partial fulfillment of the requirements for the degree of DOCTOR OF PHILOSOPHY

in

NURSING

by

Nola Holness

2014 
To: Dean Ora Strickland

College of Nursing and Health Sciences

This dissertation, written by Nola Holness, and entitled The Effects of Resilience and Social Influences on Preventing Repeat Adolescent Pregnancies in Parenting Adolescent Mothers, having been approved in respect to style and intellectual content, is referred to you for judgment.

We have read this dissertation and recommend that it be approved.

\begin{tabular}{r}
\hline Amy Paul-Ward \\
\hline Sandra Lobar \\
\hline Deborah \\
Sherman \\
\hline Luz Porter, Major \\
Professor
\end{tabular}

Date of Defense: March 27, 2014

The dissertation of Nola Holness is approved.

Dean Ora Strickland College of Nursing and Health Sciences

Dean Lakshmi N. Reddi University Graduate School

Florida International University, 2014 


\section{DEDICATION}

First, I give thanks to God for His indescribable gift of grace in sustaining me through this incredible journey to the completion of the $\mathrm{PhD}$ in nursing degree. I thank Dr. Porter, my Dissertation Chair, who has been a tower of encouragement, unfailing guide, and wonderful support from the very first class in the $\mathrm{PhD}$ program. I am truly grateful for her as a mentor who with gentle force stretched my academic capacities to incredible heights.

Dr. Paul-Ward, a member of my Dissertation Committee broadened my anthropological horizons on the plight of vulnerable adolescent populations. I will always be grateful for her insight and wit in guiding me to view people through "culture-colored" lenses. I salute Dr. Lobar, a member of my Dissertation Committee for expanding my borders in conceptual and theoretical adolescent developments. I am indebted to Dr. Sherman for her wisdom and statistical knowledge which she imparted with such gracious encouragement. Dr. Patsdaughter, a member of my Dissertation Committee is gone but not forgotten. She will always live on in my memories and my work for her statistical and editorial guidance throughout my $\mathrm{PhD}$ development.

Finally, I could not have completed this program without the help and support of my family. My mother and my husband gave of themselves to allow me room to grow. My boys handled the many roles of their mother with such maturity; reminding me that “though I am a student, a teacher, and a midwife, I am always a loving mother" What better gift could I ask for...I dedicate this dissertation to you all. 


\section{ACKNOWLEDGMENTS}

I wish to thank Ivania Castillo-Morris, Masters of Science in Nursing, graduate student at the College of Nursing and Health Sciences, FIU, who gave of her time to be a research assistant on this project. Her help was invaluable especially in reviewing Spanish documents. Her willingness and enthusiasm as part of the research team was remarkable.

Many thanks to Dr. Jianbin (Vincent) Zhu, Statistical Coordinator, at the University Graduate School, FIU, who provided statistical guidance for this research study. This study was supported by an extramural research grant, the Undine Sam's Research Grant from the Florida Nurses Foundation for $\$ 500.00$.

I am grateful for the assistance of the nurses, nursing assistants, and secretaries on the postpartum units who endured my many calls and visits for participants' recruitment and data collection. Last, but by no means least, a heartfelt thank you to the adolescent mothers who participated in this study. I pray that resilience and positive social influences may enhance the lives of these young women as they move forward to successful adulthood. 


\section{ABSTRACT OF THE DISSERTATION \\ THE EFFECTS OF RESILIENCE AND SOCIAL INFLUENCES ON PREVENTING REPEAT ADOLESCENT PREGNANCIES IN PARENTING ADOLESCENT MOTHERS \\ by}

Nola Holness

Florida International University, 2014

Miami, Florida

Professor Luz Porter, Major Professor

Every year, 16 million women aged 15 to 19 years give birth globally. Adolescent births account for $11 \%$ of all births globally and $23 \%$ of the overall burden of disability and diseases due to pregnancy and childbirth. In the United States, 750,000 adolescents (15-19 years) become pregnant each year, making the United States the developed country with the highest rates of adolescent pregnancy. The economic burden of adolescent pregnancy in the U. S. is $\$ 7-15$ billion per year.

Adolescent pregnancy brings risks associated with pregnancy induced hypertension, preterm infants, maternal and neonatal mortality. Social factors include poverty, low educational levels, alcohol, and drug use. Between $30-50 \%$ of adolescent mothers who have a first birth before age 18 years will have a second child within 12 to 24 months. Subsequent adolescent pregnancies compound fetal and maternal risks. Many vulnerable adolescent mothers succumb to external pressures and have a repeat adolescent pregnancy while others are able to overcome the challenges of an adolescent pregnancy and prevent a repeat adolescent pregnancy. 
This cross sectional survey designed study investigated the effects of resilience and social influences on contraceptive use or abstinence by Black and Hispanic adolescent parenting mothers to prevent a repeat adolescent pregnancy. 140 adolescent mothers were recruited from three postpartum units of a tertiary hospital system in Miami, Florida. The Wagnild and Young Resilience Scale and the Adolescent Social Influence Scale were used to measure resilience and social influences, respectively. Demographic data, length of labor, plan for contraceptive use or abstinence were measured by an investigator developed instrument.

Point biserial correlation showed a significant positive correlation between Black adolescent mothers' resilience and contraceptive use $(r=.366, \mathrm{p}<.001)$. Logistic regression showed that Black adolescents were 3.6 times less likely than Hispanics to use birth control. $\mathrm{X}^{2}(11, \mathrm{~N}=133)=27.08, \mathrm{p}=.004 .(\mathrm{OR}=.28)$. These results indicate a need for interventional strategies to maximize resilience in parenting adolescents to prevent a repeat adolescent pregnancy. 


\section{TABLE OF CONTENTS}

CHAPTER

PAGE

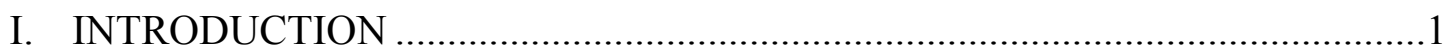

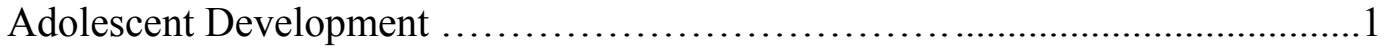

Adolescent Developmental Tasks ................................................................2

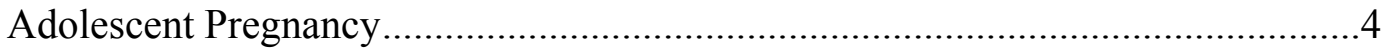

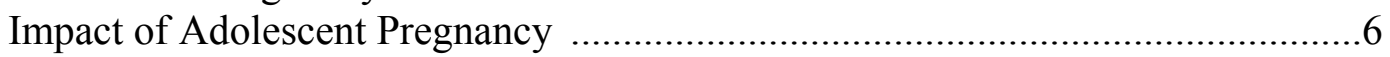

Repeat Adolescent Pregnancy......................................................................

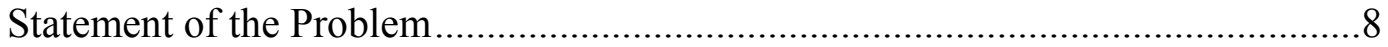

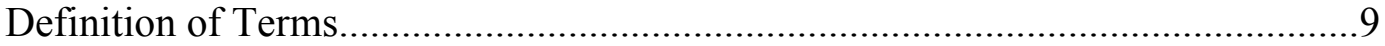

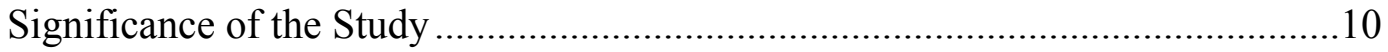

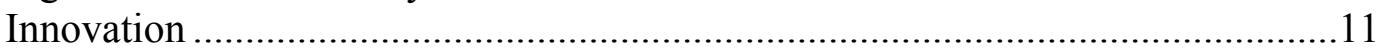

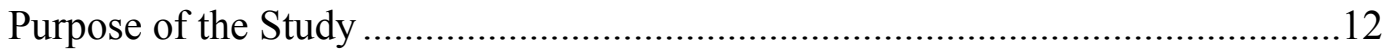

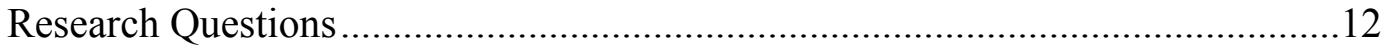

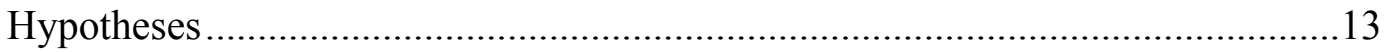

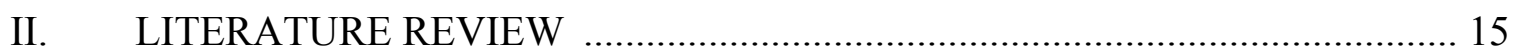

Socio-demographic Impact on Repeat Adolescent Pregnancies.............................15

The Impact of Length of Labor on Repeat Adolescent Pregnancies .....................17

Measures to Prevent Repeat Adolescent pregnancies...........................................18

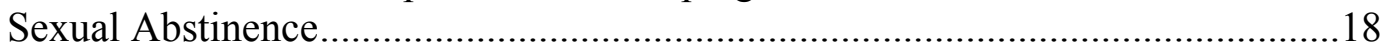

Contraceptive Use among Adolescent Mothers...................................................19

Community, School, and Home-Based Interventions..........................................25

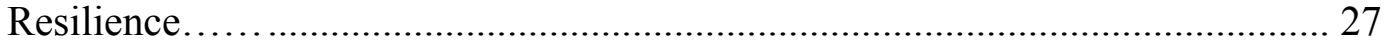

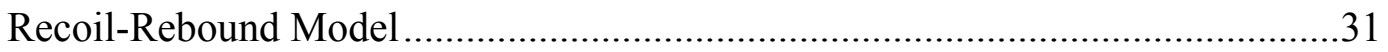

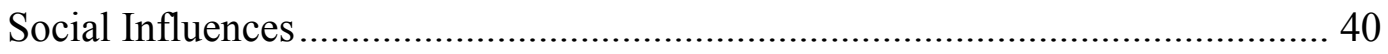

Theories Significant to Repeat Adolescent Pregnancies .......................................43

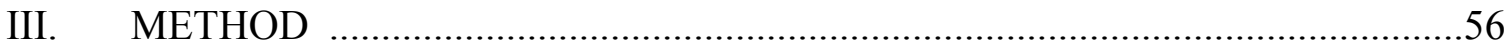

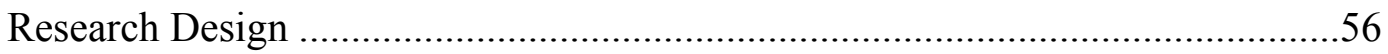

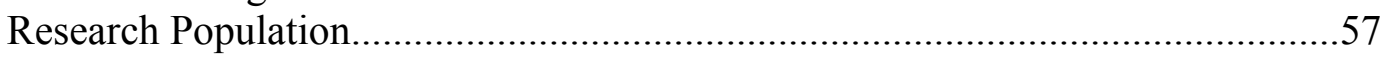

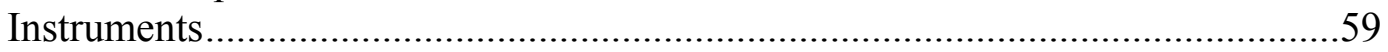

Data Collection Protocol ...........................................................................66

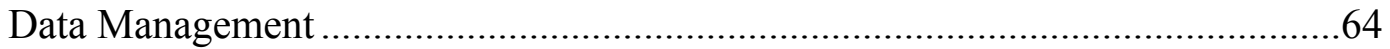

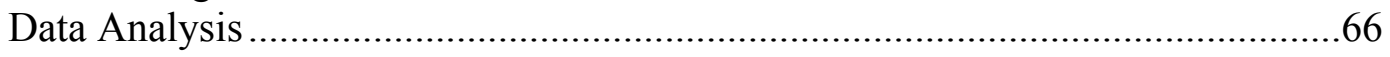

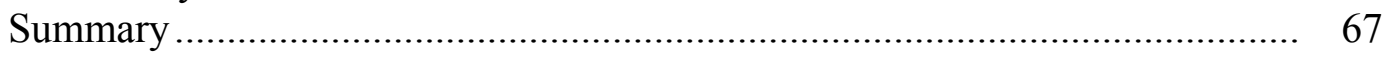

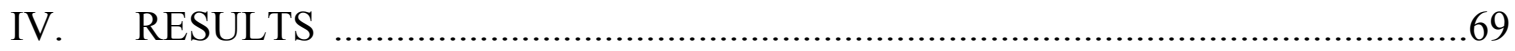

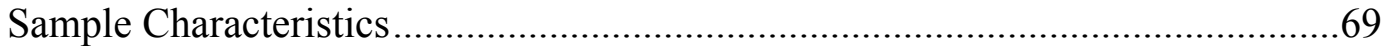

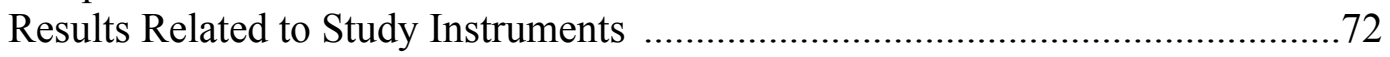

Research Questions and Related Hypothesis Testing ........................................78

Findings Related to Open Ended Questions ......................................................85 


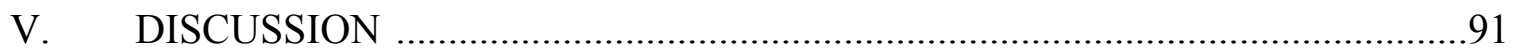

Discussion of the Findings ........................................................................... 92

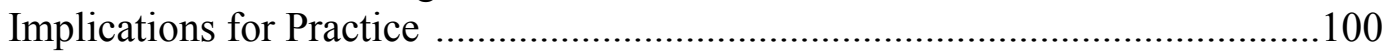

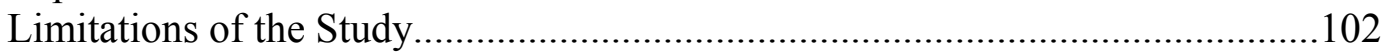

Recommendations for Future Research ....................................................102

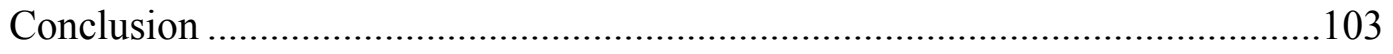

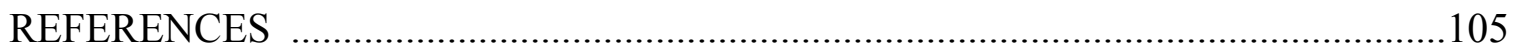

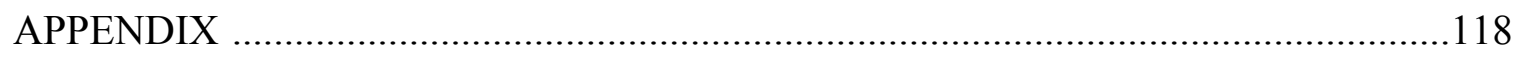

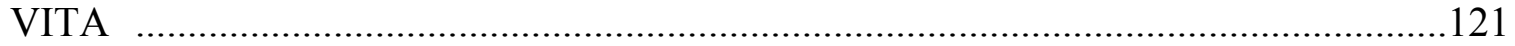




\section{LIST OF TABLES}

TABLE

1. Demographic Distribution of Black and Hispanic Adolescent Mothers......70

2. Resilience Scales Scores for Black and Hispanic Adolescent Mothers.......72

3. Reliability Estimates for the Resilience Scales.........................73

4. Social Influence Scale Scores for Black and Hispanic Adolescent Mothers. 74

5. Social Influence Overall Item Analysis for Black and Hispanic Adolescent Mothers............................................. 75

6. Hispanic and Black Adolescent Mothers' Social Influence Scores........ 76

7. Reliability Estimates for the Social Influence Scale.................. 77

8. Social Influences Scale Inter-item Correlation Matrix................... 77

9. Social Influences Scale Item-Total Statistics......................... 78

10. Point-Biserial Correlations between Resilience and Preventing a Repeat Adolescent Pregnancy.....................................8 81

11. Effects of Resilience on Contraceptive Use by Parenting Adolescent Black and Hispanic Mothers.

12. Effects of Resilience on Contraceptive Use by Parenting Adolescent Mothers when Independent Variables were held Constant...................... 84

13. Adolescent Mothers' Responses on Labor, Delivery, and Postpartum Experiences................................................ 86

14. Adolescent Mother's Responses on Support during Labor, Delivery and Postpartum 


\section{CHAPTER I}

\section{INTRODUCTION}

Adolescent pregnancy is an international and national dilemma. There are 300 million adolescents worldwide and every year 16 million women aged 15 to 19 years give birth, accounting for approximately $11 \%$ of all births (World Health Organization [WHO], 2009). In the United States, adolescent pregnancy remains a major health problem (Guttmacher Institute, 2010). There are developmental tasks to be accomplished as adolescents transition from various phases of adolescence into adulthood (Klang \& Fuligni, 2009). Leading psychologist Erickson (Harder, 2002) recognized that adolescents search for their own identities and engage in moral and social interactions to define their ideals and philosophies of life. Many adolescent girls, including minority groups such as Blacks (Afro-Caribbean and African-American) and Hispanics may be vulnerable to social pressures and led by external influences into high risk behaviors resulting in unplanned adolescent pregnancies (Patsdaughter, Kelley, Babington, \& Dyer, 2005; Ventura \& Hamilton, 2011). Adolescent pregnancies result in significant national and international challenges to individuals, families, and societies.

\section{Adolescent Development}

Adolescence is defined as individuals aged 10-19 years (WHO, 2009) with young people considered to be ages 10-24 years. The American Academy of Child and Adolescence (AACA, 2008) views ages 11-21years as the adolescent period. There are variations, as well, in the demarcation of $\mathrm{t}$ 
he ages of each stage of adolescence development (Gutgesell \& Payne, 2004; AACA, 2008). Generally, the three phases of adolescent development are: early (11-13 years), middle (14-18 years), and late (19-21 years). Hazen, Schlozman, and Beresin (2008) argued against using age norms to define adolescence. Instead, they declared that adolescents should be defined by the developmental tasks that are acquired during this phase of life.

\section{Adolescent Developmental Tasks}

Adolescents have physical, cognitive, socio-emotional, and moral goals to accomplish during their transition to adulthood (AACA, 2008; Hazen, Schlozman \& Beresin, 2008). Early adolescents experience puberty with physical changes of increased height, weight, growth and maturation of sexual characteristics. Increased growth of body hair, oil production in hair and skin, and perspiration occurs in both sexes. During puberty, girls experience hip and breast development and menstruation. Boys develop deeper voices, enlargement of testicles and penis, and ejaculation. Greater sexual awareness and interest occur among early adolescents (AACA ADD.

Cognitive changes for the early adolescent encompass increased capacity for abstract thinking, however they remain present oriented with limited concerns for the future. Hence, they are more vulnerable to engage in high risk behaviors than older adolescents. For example, Connolly and McIsaac (2008), in their study of 1357 young people, found that early adolescents (11-13 years) who engaged in romantic relationships (which may or may not be sexual) have increased risks for school difficulties and depression than older adolescents. 
Social and emotional changes are very significant for the early adolescent. Feelings of self-consciousness and awkwardness about body are heightened as early adolescents develop a sense of identity. This greater need for a sense of personal identity coincides with the beginning of an emotional separation from their parents. Early adolescents begin to recognize that their parents are not perfect; they may even have increased conflicts with parents with rule and boundary testing. While early adolescents have a desire for privacy and independence, many return to childish behaviors when faced with stressful situations. At this stage adolescents are beginning to have some moral thinking and are concerned about how they are viewed by others. Friends begin to have a profound influence on the early adolescent who now begins to identify with a peer group (AACA, 2008; Hazen et al., 2008).

The middle adolescent typically has completed puberty with girls entering a quiet period of physical changes, while boys continue to experience growth. There is continued increase in abstract thinking, as these middle adolescents begin to set goals, and think about their remaining life. The socio-emotional development of the middle adolescent involves intense self-awareness as they change their poor self-concept and develop reasonable expectations of themselves. They continue to have attachment and dependence on friends, develop feelings of love and passion, and continue their independence from their parents. Connolly and McIsaac (2008) found that middle adolescents had less break up in their romantic relationships $(72 \%, \mathrm{n}=409)$ compared to early adolescents $(78 \%, \mathrm{n}=533)$. Moral reasoning continues to expand in middle adolescence (AACA, 2008; Hazen et al., 2008). 
The late adolescent females are usually fully developed physically, while young men continue to increase in height, weight, muscle mass, and body hair. The late adolescent has the ability for delayed gratification, can think about the future, can evaluate his or her personal experiences and process their ideas and thoughts. Their social and emotional development involves a more established sense of identity and emotional stability and can show more concern for others. Peer relationships remain important and the late adolescent will now develop more sustained relationships. Connolly and McIsaac (2008) reported that late adolescents were less likely $(66 \%, \mathrm{n}=$ 223) than middle adolescents to have a dissolution of their romantic relationships. The need for independence and self-dependence is still paramount, nevertheless; the traditions and cultural norms that the adolescent experienced in earlier years may now become important once more (AACA, 2008; Hazen et al., 2008).

According to Casey, Getz, and Galvan (2008), imaging studies have demonstrated that developmental maturation occurs in the brain of the adolescence. The authors purported that a more mature limbic system (pleasure seeking) and a less developed prefrontal cortex (controlling behaviors), while not seen as sole contributors to the impulsivity and high risk actions of adolescents may explain some of the activities of adolescents including unprotected sex resulting in unplanned pregnancies.

\section{Adolescent Pregnancy}

By age 18 years, one in five girls has given birth, and in the poorer regions of the world, one in three girls become a pregnant adolescent (WHO, 2012). More than $50 \%$ of adolescent births occur in sub-Saharan Africa, $18 \%$ in Latin America and the Caribbean, and $2 \%$ in China. Most of these births occur in low to middle income countries, mostly 
among underprivileged populations. Most adolescent births occur in Bangladesh, Brazil, the Democratic Republic of the Congo, Ethiopia, India, Nigeria, and the United States, the developed country with the highest rate of adolescent pregnancies (WHO, 2009).

The United Nations (2012) noted that adolescent pregnancy remains a problem for many regions. Not much change has occurred in some regions between 1990 and 2009. In sub-Saharan Africa, per 1,000 adolescent women, 126 gave birth in 1990 compared to 120 in 2009. In the Caribbean, adolescent pregnancy rate was 80 in 1990 and 69 in 2009. Overall, for developed countries, there were 34 per 1,000 births in 1990 and 23 in 2009. For developing regions, 64 births per 1,000 occurred in 1990 compared to 52 in 2009 (United Nations, 2012).

Here in the United States, about 750,000 adolescents ages 15-19 become pregnant each year (Guttmacher Institute, 2013). Since 1970, adolescent pregnancies increased by $21 \%$ per year with a pregnancy rate of 71 pregnancies per 1,000 women and a peak rate of 116 per 1,000 women in 1990 (Guttmacher Institute, 2010). While there was a consistent drop in rates since 1990, in 2005 there was a three percent increase in adolescent pregnancy rates. Between 1990 and 2005, the overall adolescent pregnancy rate dropped $41 \%$. Black adolescents had a $45 \%$ decline in pregnancy rates. During that same time, the White adolescent pregnancy rate declined 50\%. Hispanics adolescents had a $26 \%$ decline in pregnancy rates. Since 2006 , all races had an increase in adolescent pregnancy rates. (Guttmacher Institute, 2010). In 2008, adolescent pregnancy rates fell to a record low of 68 per 1,000 females (Guttmacher, 2013). New Mexico had the highest 
adolescent pregnancy rates, along with Mississippi, Texas, and Nevada. Rates were lowest in New Hampshire, Vermont, and Minnesota (Guttmacher, 2013).

Pregnancy outcomes may be induced abortions, spontaneous fetal losses, or live births. In 2008, in the United States, $26 \%$ of all adolescent pregnancies ended in induced abortions, $15 \%$ in fetal losses, and 59\% in live births (Guttmacher Institute, 2013) The latest report from the National Center for Health Statistics (Ventura \& Hamilton, 2011) showed declining adolescent births in 2009. Nevertheless, even with this decline, the U. S. adolescent pregnancy and birth rates still remain the highest among developed countries (Ventura \& Hamilton, 2011). When compared to Canada and Sweden, the rates in the United States $(68: 1,000)$ are more than twice the rates in Canada $(28: 1,000)$ and Sweden (31:1,000) (Guttmacher Institute, 2013).

Additionally, significant racial disparities have persisted in adolescent pregnancy and birth rates. In 2008, Hispanic and Black adolescents had 107 and 117 pregnancies per 1,000 females respectively, compared to 43:1,000 for White adolescents. In 2009, adolescent births were reported as Whites having 11; Blacks: 32, and Hispanics: 41 per 1,000 females (Guttmacher Institute, 2013; Ventura \& Hamilton, 2011). Black and Hispanic adolescents (ages 15-19 years) accounted for $60 \%$ of adolescent births in the United States in 2009 (Centers for Disease Control and Prevention [CDC], 2011).

\section{Impact of Adolescent Pregnancy}

Adolescents account for $23 \%$ of the overall burden of disability and diseases due to pregnancy and childbirth (WHO, 2009). Adolescent pregnancy creates risks associated with low birth weight infants (i.e., less than 2,500 grams), neonatal deaths from acute infections, Sudden Infant Death Syndrome (SIDS), and maternal mortality. These rates 
are two to three times higher than those for adult women. Other medical complications include poor maternal weight gain, prematurity (i.e., births at less than 37 weeks), pregnancy-induced hypertension, anemia, and sexually transmitted infections (STIs). Social issues related to adolescent pregnancy are poverty, unmarried status, low educational levels, smoking, drug use, and inadequate prenatal care (Klein and the American Academy of Pediatrics Committee on Adolescents, 2005). Adolescents from minority groups experience greater health disparities and are at higher risks for unplanned pregnancies. Adolescent childbearing cost U.S. taxpayers $\$ 9$ billion per year (Healthy People.gov 2020, 2012). The National Campaign to Prevent Teen and Unplanned Pregnancy (2011) outlined this cost as related to health care cost, foster care costs, incarceration of children of adolescent mothers, and lost revenue.

\section{Repeat Adolescent Pregnancy}

Once an adolescent has one infant, she is at increased risk of having another. Sangalang, Barth, and Painter (2006) predicted that between 30-50\% of adolescent mothers who have a first birth before age 18 will have a second child within 12 to 24 months. According to Klein and the American Academy of Pediatrics Committee on Adolescence (2005), 25\% of adolescent births in the United States were not first births. Some adolescents have a third birth (13\%) or fourth to sixth child (2\%). Hispanic and Black adolescents are 1.5 times more likely than Whites to have a repeat birth (CDC, 2013).

Repeat adolescent pregnancy compounds the problems for the mother and her children. There is the risk of poor birth outcomes, lower levels of education, and living in poverty or remaining on welfare for the adolescent with more than one child (Sangalang 
et al., 2006). Outlined in the United Nation's Millennium Goal \#5 is the concern that adolescent pregnancy carries the highest maternal mortality and morbidity which increases with each subsequent pregnancy (United Nations, 2012).

\section{Statement of the Problem}

Adolescent pregnancy remains a global and national challenge. The physical, psychological, social, and economic costs of adolescent pregnancy herald the need for strategies to reduce or prevent adolescent pregnancies, and more so repeat adolescent pregnancies $\mathrm{WHO}, 2009)$. The need for interventions is greatest among minority adolescent populations with significant pregnancy and birth disparities. Contraception, community, home, and school based interventions are measures used to prevent repeat adolescent pregnancies ( Blank, Baxter, Payne, Guillaume, \& Pilgrim, 2010; ) Nevertheless, the United States continue to have the highest rates of adolescent pregnancies for developed countries (Guttmacher Institute, 2010).

The challenges of the adolescent parent for self-development while caring for her offspring can be mediated by her internal resilience and her responses to external social influences. Utilizing resilience and social influences concepts, this quantitative study will investigate the effects of resilience and social influences on Black and Hispanic parenting adolescent mothers' use of contraception or abstinence to prevent a repeat adolescent pregnancy. The overarching theory for this study is the Recoil-Rebound Model which is an adaptation of the Recoil-Rebound Resilience Theory of Teen Pregnancy Prevention (Porter \& Holness, 2011). The theory addresses the pregnant adolescent who could recoil to a repeat adolescent pregnancy or rebound to prevent a 
repeat adolescent pregnancy. The overall outcome variable is preventing a repeat adolescent pregnancy. In this study, the concept of preventing a repeat adolescent pregnancy is operationalized by two sub categories, namely, contraceptive use or sexual abstinence by the parenting adolescent mother. The Recoil-Rebound Model has a focus on resilience as well as social influences in preventing a repeat adolescent pregnancy. Using all these concepts, this study will address the problem of adolescent pregnancies in vulnerable populations and the effects of resilience and social influences on preventing repeat adolescent pregnancies.

\section{Definition of Terms}

\section{Adolescent}

As defined by the World Health Organization (WHO, 2009), adolescents refer to individuals ages 10-19 years. Adolescents transition through early, middle, and late adolescence with physical, socio-emotional, cognitive, and moral development.

\section{Adolescent Pregnancy}

A pregnancy that occurs in individuals ages 10-19 years (WHO, 2009).

\section{Repeat Adolescent Pregnancy}

A subsequent pregnancy that occurs in individuals ages 10-19 years after an initial pregnancy within the adolescent period (WHO, 2009).

\section{Adolescent Resilience}

The assets and resources utilized that enable some adolescents to overcome the negative effects of risk exposures (Fergus \& Zimmerman, 2005). Resilience was measured by the adolescent mother's score on the Resilience Scale. Higher scores signify greater resilience. 


\section{Social Influences}

A change that occurs in an individual's thoughts, feelings, attitudes, or behaviors that results from some interaction with another individual or a group (Rashotte, 2009). Social influences was measured by the adolescent's total score on the Adolescent Social Influence Scale, reflecting the degree of influence of parent, family, father of the baby, peers, school, and church on the adolescent. Higher scores indicate greater social influences.

\section{Sexual Abstinence}

"Postponing sex, or never had vaginal sex, or refraining from further sexual intercourse, if sexually experienced" (Santelli et al., 2006, p. 73). Sexual abstinence was measured by an investigator developed instrument with respondents indicating whether or not they plan to remain abstinent to prevent a repeat adolescent pregnancy.

\section{Contraceptive use}

The use of temporary, long term, or permanent methods to prevent pregnancy (International Planned Parenthood Federation, 2012). Contraceptive use was measured by an investigator developed instrument with respondents indicating whether or not they plan to use contraception to prevent a repeat adolescent pregnancy. Participants could also select their intended type of contraception from the list provided on the form.

\section{Significance of the Study}

This study aimed at examining resilience and social influence on vulnerable adolescent mothers' abstinence or contraceptive use to prevent a repeat pregnancy sought to generate comprehensive empirical knowledge toward policies and practices for improved adolescent health care. Many studies explored the internal resilience of 
adolescent mothers, while others addressed the external forces that influence adolescent mothers having a repeat pregnancy. No single study was found that addressed these multiple influences, both internal and external that have an impact on minority adolescents having a repeat pregnancy. This study addressed many of the key concepts affecting adolescent pregnancy and provided further foundations for effective and relevant interventions in addressing the costly national dilemma of unplanned adolescent pregnancies. Preventing a repeat adolescent pregnancy would facilitate the goal of improving the reproductive health of minority adolescent populations.

It was projected that the aims of this study would make notable contributions to the body of knowledge on adolescent maternal and child health by providing valuable empirical evidence for preventing or reducing adolescent pregnancies. The outcomes of this study would influence the development of treatments, services, and preventative interventions to arrest the debilitating effects of adolescent pregnancy and repeat pregnancy during adolescence for multicultural vulnerable populations. This study was timely and provided vital data on the costly dilemma of adolescent pregnancy since the United States continues to have the highest rates in the developed world.

\section{Innovation}

This study was innovative for several reasons. First, this study created a shift in current research from narrower studies that addressed either the internal factors or external factors. A wider perspective was employed in this study addressing both internal and external factors as influences on vulnerable adolescent mothers' abstinence or contraceptive use to avoid a repeat pregnancy. Second, although this topic had been well researched, most studies included samples composed of predominantly Mexican heritage 
and African American adolescents. The sample for this study consisted of Black and Hispanic adolescents and included Hispanic adolescents from several Latin American backgrounds (for example, Nicaragua, Honduras, and Santo Domingo) as well as incorporate Afro-Caribbean ethnic and racial subgroups.

Additionally, the novel approach of this study included a comprehensive instrument used for the first time in this study with a Black sample to measure social influences. Finally, the body of knowledge from this project and subsequent related studies would aid in refining interventional approaches toward reducing adolescent pregnancy in the United States.

\section{Purpose of the Study}

The purpose of this study was to investigate the effects of resilience and social influences (i.e., relationship with parents, family, peers, father of the baby, church, and school) on abstinence and contraceptive use in preventing a repeat pregnancy among Black and Hispanic parenting adolescent girls. The study examined both internal and external factors influencing vulnerable adolescent mothers' abstinence or contraceptive use in preventing a repeat pregnancy. This study sought to provide comprehensive scientific knowledge toward improved clinical practice for nursing and other health professions involved in adolescent health care.

\section{Research Questions}

1. What is the difference in resilience scores between Black and Hispanic parenting adolescent mothers?

2. What is the difference in social influences scores between Black and Hispanic parenting adolescent mothers? 
3. What is the relationship and effect between resilience and preventing a repeat adolescent pregnancy (contraceptive use or abstinence) for Black and Hispanic parenting adolescent mothers?

4. What is the relationship and effect between social influences and preventing a repeat adolescent pregnancy (contraceptive use or abstinence) for Black and Hispanic parenting adolescent mothers?

5. What is the effect of mother's age, race, socioeconomic status, education, length of labor, resilience, and social influences on preventing a repeat adolescent pregnancy (contraceptive use or abstinence) for Black and Hispanic parenting adolescent mothers?

\section{Hypotheses}

1. Black and Hispanic parenting adolescent mothers are different in their resilience scores.

2. Black and Hispanic parenting adolescent mothers are different in their social influences scores.

3. Higher resilience in Black and Hispanic parenting adolescent mothers will increase the likelihood of preventing a repeat adolescent pregnancy.

4. Higher social influences on Black and Hispanic parenting adolescent mothers will increase the likelihood of preventing a repeat adolescent pregnancy.

5. Higher resilience and social influences will increase the likelihood of Black and Hispanic parenting adolescent mothers preventing a repeat adolescent pregnancy when the effects of mother's age, race, socioeconomics, education, and length of labor are held constant. 


\section{Summary}

Despite much research and many interventions, the United States remains the only developed country with the highest rate of adolescent pregnancy. Repeat adolescent pregnancy carries further physical, psychological, and social burdens with astronomical costs to society. The focus of this study is the effect of resilience and social influences on preventing a repeat adolescent pregnancy in Black and Hispanic parenting adolescents. 


\section{CHAPTER II}

\section{LITERATURE REVIEW}

This chapter presents an overview of some of the socio-demographic variables that have an impact on repeat adolescent pregnancy. Interventions that have been implemented to prevent repeat adolescent pregnancies are examined. Resilience, social influences, and significant theories associated with repeat adolescent pregnancies are reviewed.

\section{Socio-demographic Impact on Repeat Adolescent Pregnancies}

The adolescent mother is faced with the tasks of self-development, parenting, and preventing an unplanned repeat pregnancy. A repeat adolescent pregnancy has escalating social and economic burdens affecting the adolescent, her family, community, and society at large (Rosengard, 2009). A repeat adolescent pregnancy is likely if the adolescent is very young at first pregnancy, was married during the adolescent period, deliberately conceived the first pregnancy, and/or had a poor obstetrical outcome with the first pregnancy (Crittenden, Boris, Rice, Taylor, \& Olds, 2009). Adolescents with poor family support and low educational level of her mother who was an adolescent mother herself are associated with repeat births (Crittenden, et al., 2009). These authors added that predictors of a repeat pregnancy for Black adolescents included late age at menarche, aggressive tendencies, and negative life experiences. Meade, Kershaw, and Ickovics (2008) in their study of adolescents born to adolescent mothers in the United States reported that maternal birth age, maternal education, parental marital status at age two, poverty, and poor school performance, as well as Hispanic race were significant factors for adolescent pregnancy. 
Gee and Rhodes (2007) posited that low income minority parenting adolescents have unique life event stressors. Planning to have a baby within 5 years, not using long term contraceptive within three months of delivery, poor relationship with the father of the baby within the first three months of delivery, being 3 years younger than the father of the first baby, experiencing intimate partner violence within 3 months of delivery, not being in school 3 months after delivery, and having many friends who are also adolescent parents are socio-demographic factors associated with a repeat adolescent pregnancy (Raneri \& Wiemann, 2007).

Tobey, Hillman, Anagurthi, and Somer (2011) identified that Hispanic adolescents were more likely to become adolescent parents than other race/ethnicities. Frank, Cerda, and Rendon (2007) explored the social milieu of Hispanic adolescents living in concentrated immigrant communities in Los Angeles and reported that with above average levels of poverty, there was above average negative neighborhood effect of substance abuse and delinquency. They noted that assimilation of the culture had an impact on the health behaviors and risks of minority adolescents.

Of the 14.6 million children under 18 years who are in impoverished families, one-half are African Americans (Aronowitz \& Morrison-Beedy, 2004). Feeling marginalized, these adolescents were found to be more likely to engage in risky behaviors including violence, substance abuse, and sexual activity. The authors concluded that family connectedness and an environment of poverty were determinants of behaviors of African American adolescents. Additionally, Tobey et al. (2011) reported that AfricanAmerican adolescents initiate sexual activities at an earlier age than other race/ethnicities. 
Escarce (2003) pointed out that the future of a nation is linked to the outcomes of low-income adolescents. These adolescent are more likely than their affluent counterparts to lack health insurance, have increased barriers to accessing health care, and live in depressed neighborhoods and schools. The 1800 million young people (10-24 years) worldwide, representing a quarter of the world's population have the possibility of exerting significant impact on the social, economic and health futures of their world (World Health Assembly, 2011).

\section{The Impact of Length of Labor on Repeat Adolescent Pregnancies}

The labor and delivery experience of the adolescent has significance for a repeat adolescent pregnancy (Crittenden et al., 2009) yet; no recent studies were found that evaluated adolescent's length of labor and avoidance of a repeat adolescent pregnancy. When Perry, Mannino, Hediger, and Scholl (1996) compared adolescent first- time mothers with older first- time mothers, they found no difference in their lengths of labor, however; adolescent mothers were noted to have fewer delivery lacerations than older mothers. Treffers et al (2001) also identified that generally, adolescent mothers' labor course is not significantly different from older laboring women, unless the adolescent is less than 16 years old with possible narrow pelvic bones and increased labor risks. Nevertheless, it is important to determine if the length of labor experienced by the adolescent mother will have an effect on her desire to prevent a repeat pregnancy.

In summary, socio-economic status, race, age, education, and labor experience are all key socio-demographic and clinical variables in understanding adolescent repeat pregnancies. Investigation of these variables in the context of the adolescent parenting 
experience can generate empirical information to determine strategies to assist the adolescent mother prevent another pregnancy.

\section{Measures to Prevent Repeat Adolescent Pregnancies}

The decrease in adolescent pregnancy rates over the last two decades was largely related to an increase in contraceptive use (Guttmacher, 2010). Access to and use of effective contraception is a vital component of the repeat adolescent pregnancy solution. Contraception options available to adolescents include abstinence, oral contraceptives, emergency contraceptives, barrier contraceptives methods, injectable contraceptives, and the intrauterine device (American Academy of Pediatrics Committee on Adolescence, 2011).

\section{Sexual Abstinence}

Abstinence is one of the strategies proposed in this study to prevent or reduce adolescent risky sexual behaviors. Minimal data exist in the literature on abstinence as a measure to prevent a repeat adolescent pregnancy. Most studies that address abstinence and repeat adolescent pregnancy were more than 10 years old. According to Rosenbaum (2009), more than $\$ 200$ million is spent annually on abstinence programs in the United States. Adolescents' definitions of virginity and abstinence were addressed by Bersamin, Fisher, Walker, Hill, and Grube (2007) in a secondary analysis using computer assisted self-interviews of 1,105 adolescents. The researchers assigned half the group questions related to abstinence and the other half questions on virginity. The participants reported that loss of virginity was associated with vaginal and anal intercourse. An abstinence definition was more complex. More than half of the adolescents considered genital touching as a loss of abstinence and Non-whites more than Whites were more likely to 
define those who engage in vaginal intercourse as still abstinent. The authors concluded that the sexual experience of the adolescent was a strong predictor of how they defined virginity and abstinence.

Using national samples of adolescents, Rosenbaum (2009) and Martino, Elliot, Collins, Kanouse, and Berry (2008) investigated virginity pledging adolescents' sexual behavior and reported conflicting findings. Martino and colleagues concluded that pledging was associated with delayed initiation of sexual intercourse, whereas Rosenbaum posited that pledgers' sexual behavior was similar to that of non-pledgers. In both studies, findings indicated that pledgers who had intercourse were less likely to practice safer sex than non-pledgers and were at an increased risk of STIs and adolescent pregnancy. Nevertheless, as Santelli and colleagues (2006) added, abstinence is an important behavioral strategy to prevent pregnancy for adolescents. While the authors stated that abstinence in actual practice often fails to protect against pregnancy, they recommended that adolescents who wish to become abstinent, that is, "refrain from further sexual experience if sexually experienced" (p.73) be supported in their decisions. As outlined, there is a role for abstinence in reducing repeat adolescent pregnancy. Hence, there is the need for this current study to investigate adolescent mothers' desire for future abstinence as a strategy to prevent a repeat adolescent pregnancy.

\section{Contraceptive Use among Adolescent Mothers}

Contraceptive use is an effective measure used to reduce adolescent pregnancy and prevent an unplanned repeat adolescent pregnancy. Several studies were examined on post birth contraceptive use by adolescents. Blank et al., (2010) reviewed contraceptive services available to adolescents to prevent pregnancy as well as to prevent 
a repeat pregnancy. In their systematic review of school based interventions to reduce pregnancy and repeat pregnancy, the authors included interventions in schools and colleges where peer education and culturally directed social services were provided, and contraception was readily available at the school. These school-based interventions consisting of case management by culturally matched social workers with weekly group meetings offering peer education and support, as well as provision of medical care were largely successful in reducing repeat pregnancy rates (Blank, et al. 2010).

On the other hand, Wilson, Samandari, Koo, and Tucker (2011) identified barriers to continued contraceptive use in adolescent mothers. In a qualitative study of adolescent mothers and their health care providers on factors influencing the continuation of contraception, though these mothers were highly motivated in the early postpartum to start effective methods of contraception to prevent a repeat pregnancy, lack of parental support, lack of finances, and loss in continuity of care accounted for the failed continued use of contraception. Breheny and Stevens (2004) recounted the experiences of adolescents who discussed barriers that they encountered in obtaining contraception which contributed to their becoming pregnant. These adolescent mothers devised strategies that they considered effective in overcoming barriers to not have a repeat adolescent pregnancy. Having an adult to assist them in obtaining contraception as well as using several methods of contraception to reduce the risk of failure were solutions proposed to prevent a repeat adolescent pregnancy.

Adolescent girls' ambivalence toward contraception was explored by Bruckner, Martin, and Bearman (2004) including adolescents with a prior pregnancy. In this sample, $14 \%$ of the adolescents were ambivalent toward pregnancy and $20 \%$ had an anti- 
pregnant attitude. The authors demonstrated that girls with a positive attitude were more likely to have increased use than not to use a method at all. In another qualitative study with individual participant interviews, pregnant adolescents expressed inconsistent use of contraception (Spear, 2004).

In assessing changes in contraception use during the postpartum period, Kershaw and colleagues (2003) found that adolescent mothers had an increased use of hormonal contraception and condom use in the early postpartum with a decrease in hormonal contraception after the first 6 months postpartum. In contrast, non-pregnant adolescents in this study remained consistent in their contraceptive use. Thurman, Hammond, Brown, and Roddy (2007) compared use of the contraceptive injection, the patch, and oral contraceptive pills among parenting adolescents. The long acting Depot Medroxyprogestrerone Acetate (DMPA) was the most consistently used contraception in this sample. Among the adolescent mothers, the repeat pregnancy rates were significantly different: $14 \%$ for DMPA users, $29 \%$ for contraceptive pill users, and $31 \%$ for those adolescent mothers who used the patch.

\section{Use of Depot Medroxyprogesterone Acetate (DMPA) in Preventing a Repeat}

\section{Adolescent Pregnancy}

DMPA, an injectable hormonal contraceptive is one of the most used methods of birth control. DMPA is considered the most effective method in preventing an unplanned adolescent pregnancy. Omar and colleagues (2002) reported DMPA continuation rates of $63 \%$ after the first year of use and $33 \%$ after and beyond the second year of use. Another study compared mothers who used DMPA at their initial postpartum clinic visit to mothers who selected a short term method with plans for DMPA at the next visit 
(Rickert et al., 2007). Those participants in the short term contraceptive group were four times more likely to have a repeat pregnancy than those mothers who received DMPA at their initial visit. The long-acting property of DMPA as well as its effectiveness in preventing pregnancies has made DMPA an excellent option for adolescent birth control.

One main concern with the use of Depot Provera is the risk of bone

demineralization. Several studies addressed the bone mineral density changes associated with Depot Provera's use. Conclusions were made that there were changes in the bone mineral density (BMD) of Depot Provera users; however, significant increases in BMD occurred after discontinuation of the method (Scholes, LaCroix, Ichikawa, Barlow, \& Ott, 2005; Tolaymat \& Kaunitz, 2009).

\section{Other Methods of Contraception used by Adolescent Mothers}

Concern over the side effects of DMPA may lead adolescent mothers to consider other methods of contraception to prevent a repeat adolescent pregnancy. Recently, the American College of Obstetrician and Gynecologists (McNicholas \& Peipert, 2012) issued a recommendation for long acting reversible contraception including intrauterine device (IUD) and Implanon (a contraceptive single rod implantable birth control device) to become available options for adolescent use. Deans and Grimes (2009), in their systematic review of contraception for adolescent mothers found no current studies of IUD use among adolescents in the United States. IUD continuation rates were considered reassuring for adolescent in other countries with rates higher than those of oral contraceptive pills; however, pregnancy rates were similar between these two methods of contraception. Adolescent mothers' use of Implanon was studied by Lewis, Doherty, Hickey, and Skinner (2010) who concluded that Implanon users were more 
likely to continue their method compared to Depot Provera and oral contraceptive pill users. Implanon users were less likely to become pregnant (repeat pregnancy occurred at 24 months) than adolescents using pills or Depot Provera (repeat pregnancy occurred at 18 months). So, there are conflicting findings on the most effective method of contraception for adolescent mothers, hence the need for further empirical research on adolescent mother choices of birth control to avoid a repeat pregnancy.

Latka, Kapadia, and Fortin (2008) explored the importance of the female condom to 47 low income Black and Hispanic adolescents of whom $23 \%$ had been pregnant. Contraceptive availability, effectiveness, and side effects were found to be important considerations for adolescent girls. The pregnant or parenting adolescents in this study were more negative toward using the female condom than the younger girls. The authors attributed this to the older adolescents' possible previous contraceptive failure.

A school based clinic study of 91 participants aged 14 to 20 years requesting emergency contraception was conducted by Sidebottom, Harrison, Amidon, and Finnegan, (2008). The authors found that the main reasons students requested emergency contraception were lack of use of any other method, misuse of hormonal methods, and condom related problems. Notably, adolescent emergency contraceptive users varied in their sexual experience, use of contraception, and pregnancy risk. Schreiber, Ratcliffe, and Barnhart (2010) examined the effect of having an advanced supply of emergency contraception on repeat pregnancy. Repeat pregnancy rates were $13 \%$ for participants who received an advanced supply of emergency contraception and 30\% for participants who received routine postpartum care. 
Attitudes toward male condom use in minority groups was examined by KoniakGriffin, Lesser, Uman, and Nyamathi (2003) with 67\% pregnant and 33\% parenting adolescents. Only $18 \%$ of the sample had used a condom at last intercourse. From their investigation of pregnant low income Latina adolescents and communication with their mothers about condom use, Nadeem, Romo, and Sigman, (2006) suggested that concerns about preventing a repeat pregnancy led the mothers to be more explicit in their communication with their pregnant daughters than typical religious or cultural practices. Kershaw and colleagues (2003) reported that adolescent mothers were two to three times more likely than never-pregnant adolescents to consistently use condoms along with hormonal contraception. Guttmacher Institute (2013) reported that adolescent contraceptive use has increased to $78 \%$ for $2006-2010$. As noted by Spear (2004), although U.S. adolescents have increased contraceptive use, the pattern of use remains inconsistent. Hence, there is the need for further investigation to determine factors affecting adolescent mothers' contraceptive use to prevent a repeat adolescent pregnancy. In summary, contraceptive use by adolescent mothers, especially long acting reversible methods is an effective strategy in reducing repeat adolescent pregnancies; yet, U.S. adolescents have inconsistent use, lack knowledge of and access to contraceptive methods to prevent a repeat adolescent pregnancy. More data are needed on Black and Hispanic adolescent mothers' choice of contraception as a strategy to prevent a repeat adolescent pregnancy. Additionally, social influences as well as resilience need to be examined as barriers or enhancers to the adolescent mother's use of contraception. 


\section{Community, School, and Home-based Interventions to Prevent a Repeat Adolescent Pregnancy}

The problem of adolescent pregnancy, more so, a repeat adolescent pregnancy in the United States, still has no clear or simple answers. In light of the fact that this phenomenon involves medical, educational, societal, and family components, the solutions must be multifaceted and cannot focus on only one component (Key, Barbosa, \& Owens, 2001). In conjunction with contraceptive use, many interventions have community, school, or home based strategies to reduce or prevent repeat adolescent pregnancies.

Of five studies that were community based in their strategies to reduce repeat adolescent pregnancy, four demonstrated effective reductions in adolescent repeat pregnancy rates (Barnet et al., 2007; Ford et al., 2002; Omar, Fowler, \& McClanahan, 2008; Salihu et al., 2011; Sangalang, Barth, \& Painter, 2006). While community based in their focus, many of the interventions included intense home visitations. The most significant decline in repeat pregnancy rates of the community based programs was seen in the study by Omar and colleagues (2008) when adolescent mothers received prenatal, postnatal, counseling, and acute care services for herself and her baby. Salihu et al. (2011), while not finding a reduction in repeat adolescent pregnancy rates, demonstrated that younger adolescents who had access to intense community based resources had a sustained decline in primary adolescent pregnancy rates over 4 years. This is a significant finding since preventing primary pregnancies in young adolescents is vital in improving the educational and economic potential of this vulnerable population. Utilizing a abstinence-only curriculum to prevent adolescent pregnancy, Jemmott, Jemmott and 
Fong (2010) conducted a randomized controlled trial of 662 African American students in grades six and seven. The 8-hour intervention promoted the belief that abstinence can prevent pregnancy and can lead to achieving future goals. Findings were a reduced number of sexual partners and a lesser probability of sexual intercourse for the students who participated in the abstinence intervention than those in the control groups.

The studies that were home-based interventions to prevent a repeat adolescent pregnancy had conflicting results. Barnet, Liu, DeVoe, Alperovitz-Bichell, and Duggan (2007) pointed out that questions have been raised on the usefulness and cost effectiveness of home visit programs for adolescent mothers in reducing repeat adolescent pregnancies. One study showed significant lack of success and alluded to a lack of early contraception use as a main reason for program failure (El-Kamary et al., 2004). Additionally, two studies reported no improvements in adolescent repeat pregnancies during the study periods (Barnet et al., 2007; Katz et al., 2011). On the other hand, two studies demonstrated success in reducing repeat adolescent pregnancies (Black et al., 2006; Koniak-Griffin et al., 2003). Of note, one study highlighted the impact of culture on the increased benefits from the program (Middlemiss \& McGuigan, 2005). In this study, Hispanic families were felt to be more involved in the life of the adolescent mother, whereas white non-Hispanic adolescent mothers usually had a nuclear family or an individual focus, thus less family support.

The school based programs reported success in reducing the rates of repeat adolescent pregnancies, some from $25 \%$ at program initiation to $1 \%$ at 1 to 2 years after the interventions (Schaffer, Jost, Pederson, \& Lair, 2008). Other studies showed improvements in adolescent mothers' beliefs and attitudes towards a repeat adolescent 
pregnancy. Many school based programs utilized public health nurses as well as social workers to assist the adolescent mothers gain access to medical care for themselves and their babies, psycho-therapeutic peer group support, and birth control methods. While some of these school programs require a substantial cost to operate, in Key and colleagues' (2008) cost analysis, they underscored the immense savings gained (approximately $\$ 20,000$ ) when each adolescent pregnancy is prevented (Amin \& Sato, 2004; Key, Gebregziabher, Marsh, \& O’Rouke, 2008; Schaffer et al., 2008; Thomas \& Looney, 2004). So despite success at some level of school based programs, the failure of other programs to reduce repeat adolescent pregnancies warrants the need for further research of internal and external factors that influence an adolescent mother having an unplanned repeat pregnancy during adolescence.

\section{Resilience}

Vulnerable adolescent mothers can succumb to their external environmental influences and relapse to an unplanned repeat pregnancy (Patsdaughter, Kelley, Babington, \& Dyer, 2005; Ventura \& Hamilton, 2011). Many adolescents, however, are capable of utilizing the internal mechanism of resilience to rebound from the adverse outcome of an unplanned pregnancy and establish healthy behaviors to prevent a repeat adolescent pregnancy.

\section{Historical Background}

The historical perspective of resilience is rooted in the psychology of ego development and the elasticity of individuals to rebound in life (Polk, 1997). The theory of resilience began with research of children who succeeded in life despite extreme adverse experiences, in particular, the studies of Cedebald in Sweden in 1947, who 
explored children who remained healthy despite childhood handicaps. Werner, in 1955, studied children born in Hawaii into dire circumstances; yet these children survived and succeeded despite tremendous odds (Van Breda, 2001; Werner, 1992). In the development of the body of knowledge on resilience, this concept was first assumed to be a personality trait with personal qualities that led to positive outcomes. Resilience was then determined to be a process of development thus possible for all human beings (Jacelon, 1997; Peterson \& Bredow, 2009).

\section{The Concept of Resilience}

Resilience is described as a phenomenon of "positive adjustment in the face of adversity" with a context derived definition as "the process of identifying or developing resources and strengths to flexibly manage stressors to gain a positive outcome, a sense of confidence or mastery, self-transcendence, and self-esteem" (Peterson \& Bredow, 2009, p. 326). Others have contended that resilience is: "the ability to experience stress and to deal with it effectively"; successful adaptation despite risk and adversity; springing back, elasticity, and recovery"; to "do well despite living in circumstances that expose (children) to considerable risk"; the "ability to transform disaster into a growth experience and move forward"; the "ability to bounce back from adversity and go on with (their) lives", and "the ratio between the presence of protective factors and the presence of hazardous circumstances" (Burt, 2002, p. 138; Dyer \& McGuiness, 1996, p. 277; Gillespie, Chaboyer, \& Wallis, 2007, p. 125; Johnson \& Wiechilt, 2004, p. 659; Keating-Lefler \& Wilson, 2004, p. 26; Polk, 1997, p. 1; Van Breda, 2001, p. 5). 


\section{Main Terms in Resilience}

Key terms in these conceptualizations are: stress, high risk conditions, adversity, disaster, hazardous circumstances, successful or effective adaptation, transcendence or transformation, opportunity, growth, bouncing back, and moving forward. General groupings of the terms include risk and protective factors. Risk is the "heightened probability of negative outcomes among individuals possessing certain vulnerabilities, sharing exposure to certain adverse conditions" (Grigorenko et al., 2007, p. 759).

Protective factors were described by Johnson and Wiechilt (2004, p. 662) as "effective parental and other competent adult influences, personal qualities of intelligence, self-efficacy, self-worth, hopefulness, religious connection, good socioeconomic status, good school, and other community advantages". Jacelon, (1997, p. 126) summarized these protective factors as "personal characteristics, a caring adult, and a cohesive family". Rutter (1985), in one of the hallmark studies on resilience concluded that protective mechanisms, included "constitutional and experiential factors, experiences outside the home, self-esteem, structure and control, personal bonds and intimate relations, and coping skills" (p. 608).

\section{Adolescent Resilience}

Adolescent resilience focuses on the "assets and resources that enable some adolescents to overcome the negative effects of risk exposure" (Fergus \& Zimmerman, 2005, p. 399). Assets and resources include "effective parental and other competent adult influences, personal qualities of intelligence, self-efficacy, self-worth, hopefulness, religious connection, good socioeconomic status, good school, and other community advantages" (Johnson \& Wiechilt, 2004, p. 662). Risk exposure among adolescents 
includes behaviors and influences that have significant impact on health including substance abuse, risky sexual practices, violence, and negative peer pressures (Fergus \& Zimmerman, 2005).

\section{Recoil-Rebound Resilience Theory of Teen Pregnancy Prevention}

In addressing how adolescents cope with negative life happenings, Porter and Holness (2011) developed the Recoil-Rebound Resilience Theory of Teen Pregnancy Prevention (RRTTPP) which builds upon the concepts of recoil and rebound in the face of adverse events. The RRTTPP has four central concepts: the adolescent, pregnancy, recoil-rebound interactions, and resilience. The external influences of family, peer, school, church, and community are incorporated within the concepts of this theory.

Two recurring concepts that emerged from discussions on the theory of resilience are recoil and rebound. Recoil is a Middle English word dating back to the $14^{\text {th }}$ century, meaning to fall back under pressure, or to shrink back physically or emotionally, implying a movement away through shock, fear, or distaste. Other related terms are: shrink, flinch, wince, blanch, or quail (Merriam-Webster Online Dictionary, 2009d). Accordingly, rebound is another related term to recoil, meaning to spring back on, as if on collision or impact with another body as well as to recover from setback or frustration (Merriam-Webster Online Dictionary, 2009c).

In the conceptual model of Recoil and Rebound, recoil is encapsulated in adverse situations, while rebound represents the positive surge forward in life that is generated in the presence of protective factors. In understanding the human experience of recoil and rebound, imagine a rubber ball being bounced. The physics of a bouncing ball requires one to know that a ball is almost like a spring (Physics Van, 2006). Physical scientists at 
the University of Illinois further purported that when the ball is thrown against an object, like a spring, it gets compressed and deformed with potential energy being stored in the ball. This energy is released back into the ball, having almost the same speed as when it was thrown. Additionally, the recoil and the rebound of the bouncing ball are affected by many factors: carpeted or hard flooring, hard road or grassy lawn, and the material composition of the ball-whether hard or soft rubber (Physics Van, 2006).

When the ball is first thrown, the recoil causes the ball to go to a position much less than the original state. The rebound sends the ball to a much further position than the original, which is usually greater in distance than the degree of recoil, based on the forces applied. It is reasonable to state in principle that the greater the force causing the recoil, the greater the rebound. The recoil may represent negative events or experiences influencing the degree of individual elasticity, affected by inner characteristics of the individual, her life experiences, and the presence of protective factors in her environment. Rebound may represent positive outcomes, reflecting high levels of resilience.

\section{Recoil-Rebound Model}

The foundational theory for this study on prevention of a repeat adolescent pregnancy is based on an adaptation of the RRTTPP (Porter \& Holness, 2011). The original model focused on the adolescent, pregnancy, recoil-rebound interactions, and resilience with the social influences of the parents, family, peer, school, church, and community incorporated within the theory. Similarly, this study will have all the above concepts embedded in the model, however the central focus will be on the parenting adolescent mother's resilience, social influences, recoil (having a repeat adolescent pregnancy), and rebound (the use of contraception or abstinence to prevent a repeat 
adolescent pregnancy). The major adaptation of the Recoil-Rebound Model is the incorporation of the adolescent mother's social influences as a major concept.

Resilience and social influences are important concepts that may influence choices in an adolescent mother's post-delivery concerns about a repeat pregnancy. Resilience is defined as "the assets and resources that enable some adolescents to overcome the negative effects of risk exposures" (Fergus \& Zimmerman, 2005, p. 399). Developmental differences occur at each stage of adolescent development, therefore; resilience may be different for diverse age groups.

Social influence is defined as a change in an individual thoughts, feelings, attitudes, or behaviors that results from interaction with another individual or a group (Rashotte, 2009). These influences have an impact from the environment in which the adolescent lives whether attending school, or church. Social influences may encompass her relationships with parents, family, peers, and the father of the baby. The developmental stage of the adolescent mother will influence her social relationships. The adolescent mother's age (including her stage of development), race, socioeconomic status, education and length of labor will have an impact on her resilience and her social influences.

Recoil is defined as falling back under pressure (Merriam-Webster Online Dictionary, 2009d). The parenting adolescent may not have adequate protective factors and could recoil to a repeat adolescent pregnancy.

Rebound is defined as recovering from a setback or frustration (Merriam-Webster Online Dictionary, 2009c). The adolescent mother springs back from her unplanned 
pregnancy and exhibits behaviors (contraceptive use or abstinence) that enable her to avoid another adolescent pregnancy.

This model explains the risk and protective factors an adolescent mother has at her stage of adolescent development and how her internal resilience and external social influences will have an effect on her rebounding to prevent a repeat adolescent pregnancy or the likelihood of recoiling to a repeat adolescent pregnancy.

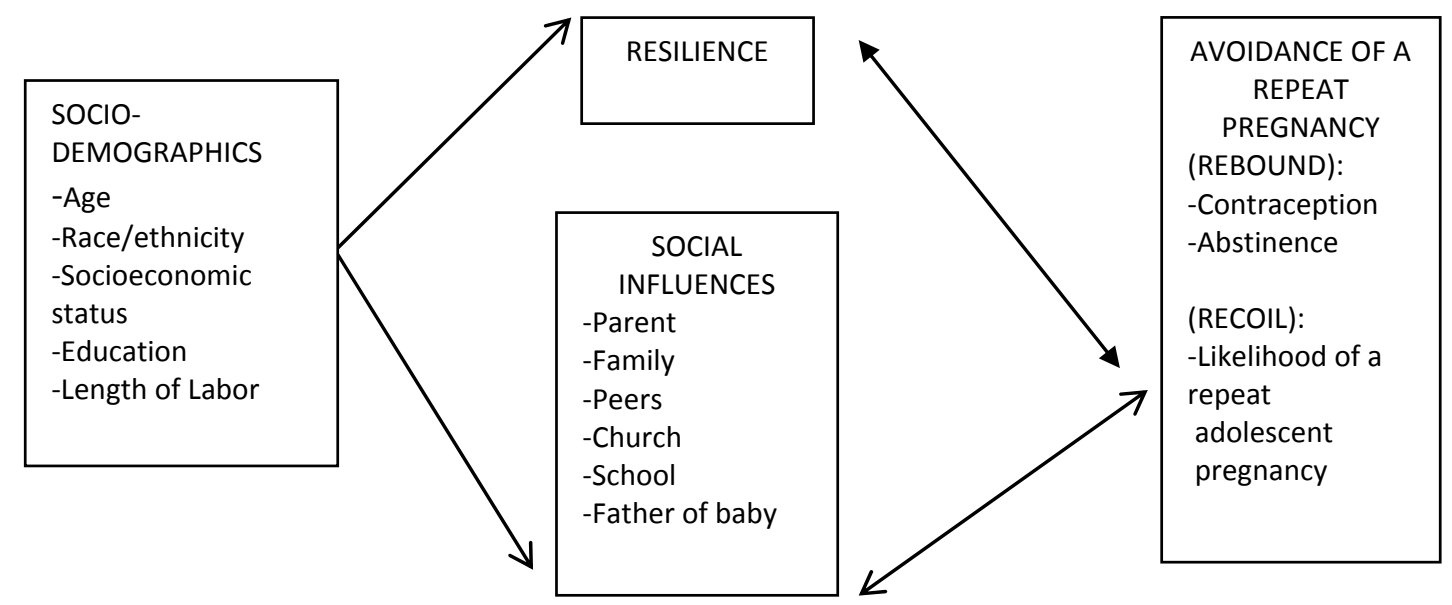

Figure 1. Recoil-Rebound Model

\section{The Adolescent Mother's Resilience}

Resilience is an internal influence for coping in the adolescent mother.

Embedded within her resilience is the additional concept of self-efficacy. As posited by Bandura (1997), self-efficacy refers to one's belief in her or his own capabilities to take 
the actions required to manage imminent situations. Role models are key to the development of self - efficacy. However, vulnerable adolescents may lack positive role models within the family, school, or peer group and, thus, may not utilize pertinent social and health promotion programs that are available through the church, school system, or the community. As such, self-efficacy is likely to be diminished.

On the other hand, if the at-risk adolescent demonstrates adequate resilience, she may cope effectively with an unplanned pregnancy, even in the absence of effective role models, support systems, and other resources. In fact, resilience appears to be the driving force in underprivileged adolescents successfully overcoming challenges in life and coping with significant stressors, such as a pregnancy. Through this process, an at-risk adolescent may achieve positive outcomes, including preventing repeat pregnancies, remaining in school, developing parenting skills, and becoming a caring mother. In a non-supportive environment, the adolescent mother with low resilience may be stuck in the recoil phase. In recognizing her unplanned pregnancy, she may view her self-esteem and body image negatively and could withdraw from social activities and friends with a prolonged recoil phase. Thus, the recoil - rebound phenomenon may be reflective of one's own resilience. It is reasonable to state that the more resilience an individual has, the faster the rebound; similarly, the less resilience one has, the slower the rebound.

Resilience in minority adolescents was highlighted in a cross-sectional secondary analysis of 443 Black female adolescents, ages 11-15 years regarding their resilience and risk taking behaviors. Aronowitz and Morrison-Beedy (2004) concluded that having a future time perspective was a mediator between connectedness to family and resilience. 
The authors recommended that mothers of adolescent girls develop a connected relationship with their daughters to promote a relationship with long term benefits.

\section{Risk and Protective Factors}

The recoil-rebound phenomenon of the adolescent response to a pregnancy may be modified by protective and adverse factors influencing the adolescent's response to challenging situations. In comparing risks and protective factors of 94 pregnant and nonpregnant mostly Mexican-Americans Latinas who were 14-19 years of age, Doğan-Ateş and Carrion-Bashan (2007) found no differences in self-esteem or locus of control between the groups or how adolescents from either group related to their parents on sexual topics. However, the non-pregnant group reported more curfew restrictions, more time playing sports, fewer relatives who had adolescent pregnancies, more frequent attendance at religious services, higher grades, and higher levels of satisfaction with friends than did the pregnant group (Doğan-Ateş \& Carrion-Bashan, 2007). Adverse factors may be past experiences with an unstable relationship with the baby's father, a history of abortion or adoption, a young maternal birth age, poverty, or poor school performance. Other adverse influences may include the adolescent's ambivalence, anxiety, depression, alcohol or drug use, social isolation, and a self-perceived violation of moral, religious, or cultural codes (Black, 2004; Black et al., 2006; Meade \& Ickovics, 2005). In the presence of these factors, the adolescent mother is likely to be stuck in the recoil stage and may continue with familiar negative behaviors such as risky sexual practices, unintended repeat pregnancies, and eventually, school drop-out.

Conversely, protective factors which may lessen the recoil phase include acceptance of the mothering role, parenting skills, self-efficacy, spirituality, 
access to positive role models, and life-training skills such as academic and vocational education (Meade, Kershaw, \& Ickovics, 2008; Raneri \& Wiermann, 2007). If these protective factors overcome adverse circumstances, the adolescent mother can enhance her resilience and rapidly turn back from recoil to rebound, prevent a repeat pregnancy and surge forward to achieve successful adulthood.

\section{Resilience Measurements}

Measuring the adolescent mother's resilience required an evaluation of several resilience scales to determine the best instrument for this study. Ahern (2006) noted that the Wagnild and Young Resilience Scale (1993) and the Connor Davidson Resilience Scale (Connor \& Davidson, 2003) were among the top scales for measuring adolescent resilience. Further review by Windle, Bennett, and Noyes (2011) rated these scales highly in psychometric properties of content validity, reproducibility, reliability, and responsiveness.

The Wagnild and Young Resilience Scale (RS) and the Connor Davidson Resilience Scale (CD-RISC) were evaluated on psychometric properties, initial studies, and subsequent use. Both scales have been documented to be reliable and valid in their original samples, and since then have had worldwide use in measuring resilience with sound psychometric properties.

The RS and the CD-RISC were both developed with adult samples; nevertheless, these two scales have demonstrated adequate psychometric properties for use with adolescent samples (Ahern, 2006; Davidson, 2010). Both scales have had national and international use in studies with diverse samples. The Wagnild and Young Resilience 
Scale has been translated into Swedish, Dutch, and Spanish. The scale has been used with European Americans, African American, Hispanics, American Indians, and Asian middle aged and older adults, including males, and adolescents samples (Wagnild, 2009). The CD-RISC has been translated into many languages including Afrikaans, Chinese, Korean, and Spanish and used with adult community groups, adolescents, students, and young adults (Davidson, 2010). Both scales have questions that are all positively worded, hence the possibility of social desirability and response bias (Wagnild, 2009).

A major distinction between the RS and the CD-RISC is how resilience is defined and measured. The RS measures resilience as a stable individual trait, whereas the CDRISC measures resilience as an outcome variable affected by other factors including therapeutic agents. While the RS use is with generally healthy samples (Wagnild, 2009), the CD-RISC has been used with psychiatric samples including suicidal and schizophrenic respondents (Davidson, 2010). Based on average numbers of words and syllables in the sentences, the RS has a lower reading level than the CD-RISC. The CDRISC is costly to obtain (i.e., $\$ 100$ for use of the scale), while the RS is free of charge and easily copied for use. The reading level of the RS is lower than the CD-RISC which may be more appropriate for the parenting adolescents in the proposed study.

The RS was initially tested on a randomly selected sample of 810 healthy senior citizens in the United States; the mean age was 71 years $(S D=6.50), 63 \%$ were female and $83 \%$ were Caucasian (Wagnild \& Young, 1993). The mean score for this sample was $147(S D=16.8)$. Results indicated a high coefficient alpha of .91 and item to total correlations between .50 and .70 . A two factor solution was extracted from factor analysis with loadings of .40 or greater with both factors accounting for $44 \%$ of the 
variance. The two factors that emerged were labeled Personal Competence and Acceptance of Self, two constructs that the authors purported were keys in the theoretical concepts of resilience (Wagnild \& Young, 1993). Items on Factor 1 encompassed "mastery, resourcefulness and perseverance" (p. 174). Factor 2 items suggested “adaptability, balance, flexibility and a balanced perspective on life" (p. 175).

\section{Subsequent Use of the Resilience Scale}

As reported by Ahern, Keihl, Sole, and Byers (2006), the RS has been used in over 18 studies with multicultural adolescent samples. Further use of the RS scale with adolescents supported strong reliability and validity. Black and Ford-Gilboe (2004) investigated 41 healthy Canadian adolescent mothers' health promotion practices for themselves and their off springs. The mean age of the mother was 20 years $(S D=1.35)$

at time of study and 17 years $(S D=1.20)$ at time of birth of child. Mean resilience score was $146.6(\mathrm{SD}=14.08)$. Reliability for the $\mathrm{RS}$ was strong in this study with a coefficient of .85. Construct validity was supported with a moderately positive correlation between the RS and the Health Option Scale $(r=.34 . p=0.01)$ and the Health Promoting Lifestyle Profile II Scale $(r=.42, p<0.001)$.

Hunter and Chandler (1999) investigated 51 healthy high school high risk students including 22 Hispanics, 20 Blacks, 6 Whites, and 3 from other racial groups. The mean resilience score was $146.6,(S D=14.1)$, similar to the score of the original sample. Gender and race did have effects on the scores. Girls scored lower than boys (4.9 versus 5.3, $p<.01)($ range $=1-7)$, and White adolescents perceived that they have lower resilience than Black or Hispanic adolescents (4.9 versus 5.2 and 5.6, $p<.01$ ) respectively. At the end of 2 weeks, posttest scores improved for the White group from 
4.9 to 6.4 with the authors surmising that the time spent with the caring adults who valued what the adolescents had to say accounted for the improvement. The Cronbach's alpha coefficient was .72 in their sample (Hunter \& Chandler, 1999).

Rew, Taylor-Seehafer, Thomas, and Yockey (2001) reported a coefficient alpha of .91 for the RS when they assessed 59 homeless adolescents with a mean age of 18.6 $(S D=1.65)$. Construct validity was supported with moderate correlations with the UCLA-Revised Loneliness Scale $(r=-.50)$ and Beck Hopelessness Scale $(r=-.47)$. Heilemann, Lee, and Kury (2003) tested a translated Spanish version of the Resilience Scale with a convenience sample of 147 women of Mexican heritage who read and wrote in Spanish. The mean age was 28 years $(S D=4.87)$. The Cronbach's alpha was .93 . Factor analysis with data from this sample was inconclusive. A positive correlation with the Life Satisfaction Scale supported the construct validity of the Spanish scale ( $r=.36, p$ $<.001)$ as well as a negative correlation with the Center for Epidemiologic Studies Depression Scale $(r=-.29, p<.001)$.

While no gold standard currently exists for measuring adolescent resilience (Windle et al., 2011), the RS is judged to be the best instrument for measuring resilience based on cost, reliability, validity, readability, and prior use with adolescent mothers. The RS scale measures resilience as a trait which is in keeping with the definition of resilience for the proposed study. The Wagnild and Young Resilience Scale is the best fit for use in the adolescent sample for the proposed study. 


\section{Social Influences}

While the internal milieu of the adolescent is an important component of her development and a key factor in preventing a repeat adolescent pregnancy, her social influences are equally significant. The central concept of the Recoil-Rebound Resilience Theory of Teen Pregnancy Prevention is the parenting adolescent who is faced with the possibility of a repeat pregnancy and subjected to influences from the external environment.

There are many external influences that impact whether an adolescent prevents a pregnancy or engages in risky behaviors that result in conception. Of these influences, parents, family, peers, school, church, and the father of the baby are usually highlighted as being important. The type of support derived from her environment will determine how she responds to a pregnancy. The parenting adolescent mother who is faced with a possible repeat pregnancy may be reared within a dysfunctional family. Erickson (Harder, 2002) pointed out that the peer group may cast a stronger influence on the behaviors of adolescent than the family since adolescents typically identify with their respective peer groups much more than with their own families. Poor peer support may lead to her dropping out of school, rejecting health promotion and disease prevention options, instead, engaging in high risk sexual behaviors that contribute to repeat pregnancies or STIs. For the vulnerable adolescent, the peer group may simultaneously serve as a source of social support but could alternately promote maladaptive behaviors.

Cook, Buehler, and Henson (2009) examined peers and parents as social influences to dissuade risky behaviors and encourage abstinence in adolescents. Although only the variables of parents and peers were measured in this 4 year 
longitudinal study of 416 families of which 91\% were European American, adolescents were noted to rely more on their parents than their peers as influences to deter sexual behaviors. This finding was similar to results found by Holness (2009), in a secondary analysis of cross sectional data from Dominican adolescents living in the United States and their counterparts living in the Dominican Republic. Parents $(n=279,39 \%)$ were found to be a stronger influence than peers $(n=277,18.5 \%)$ on the sexual behaviors of adolescents.

A significant force for adolescents faced with the problem of pregnancy may be a strong spiritual orientation. Manlove, Terry-Humen, Ikramullah, and Moore (2006) studied several dimensions of parents' religiosity and the impact on adolescents' timing of sexual initiation and contraceptive use at sexual initiation with a sample of adolescents who participated in the 1997 National Longitudinal Survey of Youth. A positive association was found between family religious activities and timing of sexual initiation among male, female, Hispanic, and white adolescents. No statistical association was found between religious attendance and contraceptive use for African American adolescents. The authors purported that sexual activity at earlier ages may be more the norm in African American communities than in white or Hispanic communities. Peer group endeavors that foster spiritual development are focused on self-reflection and helping others. These events may include church-based programs such as youth group fellowships, spiritual retreats, and community service projects.

Porter (1998) emphasized that schools have a powerful influence on the prevention and management of psychosocial and physical problems that affect adolescents. School nurses and other personnel can play key roles in providing 
adolescents with health education on sexual behaviors, prevention of STIs, and prenatal health care, motivating adolescent mothers to finish school and preventing rapid repeat pregnancies. The school is a setting where parenting adolescents may encounter positive mentors capable of encouraging formal education and continued social development of work-oriented goals and good citizenship. Parenting, safer sex education, nutrition, and physical activity as school based programs are especially beneficial to the adolescent mother.

However, the school may be lacking in adequate facilities as well as role models who are willing to provide needed support. Such deficits may be compensated by the availability of appropriate community resources and facilities. Nevertheless, some adolescents positively adapt to these negative environmental forces by becoming energized to overcome challenges in life and strengthened by adaptive personal attributes and psychosocial factors such as a healthy self-esteem, an accurate and positive body image, resilience, and self-efficacy.

The father of the baby may be a significant influence for the pregnant or parenting adolescent. While the focus of health education is usually geared toward girls to delay sexual initiation and the resulting risk of adolescent pregnancy, there is a vital need for boys to be educated and provided with strategies to delay their age at first sexual activity. Girls tend to be cosseted while boys are allowed to "roam free". Guilamo-Ramos and colleagues (2007) presented findings from focus groups of adolescents and parents from Dominican and Puerto Rican backgrounds living in New York City. Both groups of parents allowed boys more freedom than girls as "boys can take care of themselves if something bad happens" (p. 23). It is important to change this mind set and develop 
within boys a desire to delay rather than initiate sexual activities at an early age. More than two thirds of adolescent pregnancies are the result of sexual activities with a partner who is also an adolescent (Klein and the American Academy of Pediatrics Committee on Adolescents, 2005). Adolescent fathers usually have less academic preparation, higher school dropout rates, and less employment and income potential than their non-parenting peers (Klein and the American Academy of Pediatrics Committee on Adolescents, 2005). Nevertheless, support from the father of her child has a positive effect of strengthening emotional bonds and enriching the home environment of the adolescent mother (RozieBattle, 2003).

In summary, contraception, including abstinence, and interventional programs are effective strategies in reducing unplanned adolescent pregnancies. Adolescent mother's social influences and her resilience are key determinants in her ability to prevent another pregnancy. An important underpinning of all these strategies is the theoretical background to support these interventions.

\section{Theories Significant to Repeat Adolescent Pregnancies}

To comprehend the tasks of the adolescent mother and the challenges she face to prevent a repeat pregnancy, foundational theories need be explored that may explain her decisions. Several theoretical frameworks have been used in research on adolescent pregnancy to interconnect the various dimensions of this phenomenon. These theories have led to significant advances in understanding the complexity of the factors associated with adolescent pregnancies and repeat adolescent pregnancies. Porter and Holness (2011) reported that some of the most common frameworks are the social cognitive, ecological, developmental, and resilience theories. Earlier, Nitz (1999) in a review of 
theories related to adolescent pregnancy reported that most theories are social or biological in nature with focus on poverty perspective, emotional deprivation, social learning, and ecology.

\section{Family Resilience}

An important influence on the adolescent is the family. The resilience of the family will determine how an adolescent responds to life's challenges. Hawley and DeHaan (1998) defined family resilience as "the path a family follows as it adapts and prospers in the face of stress, both in the present and over time. Resilient families respond positively to these conditions in unique ways, depending on the context, development level, the interactive combination of risk and protective factors, and the family's shared outlook" (p. 7). Simon, Murphy, and Smith (2005) defined family resilience as "the ability of a family to respond positively to an adverse situation and emerge from the situation feeling strengthened, more resourceful, and more confident than its prior state" (p. 427).

Family factors have been shown to have direct and indirect influences on the individual, including family household, structure, family atmosphere, and communication. Simon and colleagues (2005) expounded on the three dimensions of family resilience: the length of the adverse situation faced by the family, the life stage during which the family encounters the challenge, and the internal and external sources of support that the family uses during the crisis. Family can be a risk factor when family situations create disordered patterns of functioning by the members. Family may be protective if there is positive nurturing, acceptance, and cohesion among the members (Hawley \& DeHaan, 1998). The cultural environment of the adolescent will also have an 
influence on her self-worth and self-esteem (Giger \& Davidhizar, 2002). In all dimensions, the cultural context in which the individual and family exist must be included in any assessment since people will revert to cultural traditions to solve life's woes (Peterson \& Bredow, 2009).

\section{Walsh's Family Resilience Framework}

The aforementioned RRTTPP is the major theory for the study. However, most adolescents exist within a family structure; hence the importance of family resilience on the parenting adolescent's ability to prevent a repeat adolescent pregnancy. One such family resilience theory is Walsh's Family Resilience Framework. One of Walsh's premises is that of the individual being understood and nurtured in the context of the family (Simon et al., 2005). Walsh's framework is appropriate for research on adolescent pregnancy since this potentially stressful time in the adolescent's life is best seen in the context of connectedness to a nurturing family or a surrogate caring adult. In developing this framework, Walsh (1996) drew on the work of Bronfenbrenner, in which the family is seen as embedded in the community of peers, school, and or work which is further nested in larger systems creating a social network. Walsh (2003) conceptualized the family as either breaking under adverse situations or being strengthened by life's crises. Walsh stated that processes used by families to cope with adversities may vary and evolve over time. In the Family Resilience Framework, three processes influence the family's resilience: the family's belief system, their organizational process, and their communication and problem solving behaviors. 
The family's belief system refers to the meaning they have of the adversity, their positive outlook, their transcendence or spiritual support in how they are strengthened during the crisis, what lessons they learn, and how they grow from the situation (Walsh, 2003). Family organization denotes a flexible structure where instead of bouncing back (since it is unlikely that the family can return to a normal life as they knew it), they can "bounce forward" to move forward. Organizational process involves being connected to each other through mutual support and commitment using social and economic resources to survive. Resources include kin and social networks, balancing financial security, and family work and constraints.

Another concept in this framework is communication and problem solving. This involves clarity in the messages sent to each other, sharing crucial information, open emotional expressions, and affirming the reality of the situation (Walsh, 2003). Open emotional expression refers to open communication, responsibility for own actions, being aware of withdrawing and anger as possible responses to the situation, and finding humor or moments of pleasure in the midst of the crisis to lift sprits. Collaborating is highlighted to define goals, to explore resources, and to have shared decision making and conflict resolution to move forward beyond the crisis.

This theory was used to explain how families maintained strong bonds during a time of upheaval brought about by an unplanned adolescent pregnancy. Duckett (2009) used Walsh's framework as the guide to address African American adolescent mothers and their families' ability to utilize processes to sustain relationships during stressful times. Eight African American adolescent mothers and their families were assessed in their development of resilience during the unplanned pregnancy and delivery. Emerging 
conclusions were "(a) reactions to the pregnancy, (b) emotions around the pregnancy, (c) belief systems, (d) unstable relationships with men, (e) impact of adolescent parenting, (f) experiences of motherhood, (g) experiences of grandparenthood, (h) socialized to early parenthood, and (i) coping” (p. 139). Communication, religion or spirituality, and support from their families and communities were the overarching themes indicating how these adolescents developed resilience. According to Duckett (2009), Walsh's theory emphasizes that a family's belief system is key in making meaning of the hardship that they were facing. Duckett further highlighted that organizational structures were needed for any family to survive their hardship with financial resources, a nurturing caring environment, and communication involving conflict resolution as vital elements in ensuring successful negotiation of the upheaval.

Resilience is an important dimension to consider as the adolescent mother navigates through adverse life events and utilizes protective factors to arrive at positive outcomes for her and her offspring. The concepts of the RRTTPP and Walsh's Family Resilience Framework will support this study to contribute knowledge to create policies and interventions to assist the adolescent mother prevent a repeat adolescent pregnancy and overcome hurdles to safely and positively arrive at adulthood.

\section{Socio-cultural Theories}

The social and cultural context in which minority adolescents exists have a major impact on their health behaviors. Reproductive and sexual health are influenced by economic, social, cultural, and educational environments in which girls are born, grow to womanhood, marry, and repeat the process in starting their own families (United Nations Population Information Network, 2001). Medical anthropologists assert that health and 
related issues are more than just biological occurrences but must be viewed in a cultural context to understand and effect change (Singer \& Baer, 2007). Whether from a national or a global perspective, health related conditions are linked to factors of the social network of the society or country (Singer \& Baer, 2007).

\section{Bandura's Social Cognitive Theory}

One widely used sociological theory related to adolescent pregnancy is Bandura's Social Cognitive Theory which underpins the influence of social factors on the adolescent's perceptions and behaviors. Bandura (1982) theorized that humans learn by observing behaviors and the consequences of those behaviors. Social learning has four components: attention, retention, behavior production, and motivation. As related to this study, the concept of attention refers the adolescent attending to the main components of the modeled behavior in order to learn by observation. In order for an adolescent to learn from the behavior, she must remember the modeled behavior. Next, through behavior production, the adolescent puts the observed behavior into action. She needs to take the action observed and use it, thus having a change in behavior. Finally, she is motivated to adopt this new behavior if it indicates that it will result in a positive outcome (Gibson, 2004). In an in-depth look at Bandura's theory, Van Breda (2001) reflected on the ability of individuals to deal with current events in their lives though a sense of personal efficacy. If there is adequate efficacy, individuals are energized to cope; but if minimal efficacy exists, then some may not be able to cope with the challenges of life. In sum, the internal mechanisms of the parenting adolescent correlate with a change in her behavior toward utilizing effective strategies to prevent a repeat unplanned adolescent pregnancy. 


\section{Giger and Davidhizar's Transcultural Assessment Model}

One framework to evaluate the cultural influences on adolescent pregnancy is Giger and Davidhizar's Transcultural Assessment Model. The premise of this theory that relates to the parenting adolescent mother is that culture guides how an adolescent girl thinks and acts, affecting her self- worth and self-esteem (Giger \& Davidhizar, 2002). There are six components to this theory:

1. Communication refers to the means by which the adolescents' culture is transmitted and preserved.

2. Space denotes the distance between individuals when they communicate. All communication with the adolescent occurs within the context of space, whether intimate, personal, social and consultative, or public zones. Rules concerning personal distance vary from culture to culture.

3. Social organization refers to the manner in which a cultural group organizes itself around the family group. The adolescent's family structure and organization, religious values and beliefs, and role assignments will depend on her ethnicity and cultural beliefs.

4. Time refers to whether the cultural group in which the adolescent identifies is past, present, or future oriented.

5. Environmental control is the adolescent's belief that she has or does not have control over nature and is able to plan and direct factors in the environment that affects them.

6. Biologic variations are the genetic variations that exist between individuals in different racial groups. There is diversity within cultural and racial groups as there is 
across cultural and racial minority groups. These are six key components in addressing minority parenting adolescents, especially those who feel marginalized with possible language barriers and limited access to resources to prevent a repeat adolescent pregnancy.

According to Andrews and Boyle (2002), pregnant Hispanics, in particular those of Mexican heritage had only $58 \%$ access to care which was much less than Blacks or Whites. The challenges some undocumented immigrants face are low literacy levels and limited access to welfare. The focus of care is to prevent infant mortality and increase access to resources in the community. Burk, Wieser, and Keegan (1995) advised that communication with Hispanic clients should occur in their primary language to assist them in accessing care and understanding care regimens. Mexican Americans tend to have a present time orientation with the concept of time loosely structured especially for individuals in the lower socioeconomic strata. Many in this ethnic group have an external locus of control with the perception of little control over their environment and health effects. Biological variations include an increased rate of cervical cancer and diabetes than in the general population. It is important that health care providers know the predominant cultural beliefs of the client in the health care setting and plan care accordingly (Burk et al., 1995).

African Americans had cultural variations with some rural Blacks viewing health as good luck, illness as God's punishment, and seeking healing from community spiritualists rather than medical practitioners (Andrews \& Boyle, 2002). African Americans in this assessment were present time oriented making preventive health care more difficult. Lower socioeconomic state, nutritional soul food, feeling of kinship, 
church dinners, home style restaurant, and high aspirations for education but limited socioeconomic status were complex factors in the lives of African Americans. Additionally, strong extended family networks and racial importance were continual issues of African Americans. Some of the biological variations for African Americans were lactose intolerance, hypertension, and sickle cell anemia (Andrews \& Boyle, 2002). Kohli and Nyberg (1995) noted that poverty was a marker for African American adolescents becoming pregnant. The authors stated that many African American adolescents live in impoverished neighborhoods with financially bleak futures, and the cost of having babies did not outweigh the rewards of not having children.

\section{Political Economy and Social Justice Theories}

Another major factor that will influence the reproductive attitudes and behaviors of adolescents is the political economic climate of a country and a community. Handwerker (1990) asserted that birth is not just a biological event but a political occurrence with individual as well as societal impact. The link between politics, economy, and adolescent pregnancy can be explored through Adam Smith's theory of political economy. Political economy is the science of the relationship between people in the society and the production, distribution, exchange, and consumption of material goods. In his theory of political economy, Adam Smith expounded on the benefits of a free economy and how justice and law interface in the realm of economy (Smith, 2005; Youngkin, 2005). He elaborated on the voluntary economic exchanges between individuals producing benefits for all involved parties. A further concept in his theory is moral philosophy in which individuals would focus not on self-promoting desires but rather virtuous acquisition of wealth to help others. 
Peterson (1991) pointed out that political economy involved the existence of power and status which can lead to privileges and disparities. The link between income inequality at the community level and adolescent births was explored by Gold, Kawachi, Kennedy, Lynch, and Connell (2001) who noted that communities with greater income inequality had "poorer population health because more unequal societies devote fewer resources to ensure the wellbeing of their less well-off members" (p. 161). Bissell (2000) presented an examination of the issue of socioeconomic status and adolescent pregnancy and suggested that while adolescent mothers were disadvantaged economically; their socioeconomic status may not be a consequence of early motherhood. The author pointed out that cultural norms and socioeconomic disparities may influence the adolescent's child bearing decisions. Family, racial/ethnic, educational background and welfare use may contribute more to her negative economic state rather than her early age at giving birth (Bissell, 2000). Political and economic issues are important in this study to provide a background for interpreting resilience and social influence scores.

In addition to political economy, social justice issues have an impact on parenting minority adolescents. Social justice is defined as the "fair and proper administration of laws conforming to the natural law that all persons, irrespective of ethnic origin, gender, possessions, race, religion, etcetera are to be treated equally and without prejudice" (Business Dictionary, 2012). From the University of California Berkley, School of Social Welfare Social Justice symposium came this working definition "Social Justice is a process, not an outcome, which (1) seeks fair (re)distribution of resources, opportunities, and responsibilities; (2) challenges the roots of oppression and injustice; (3) empowers all people to exercise self-determination and realize their full potential; (4) and builds social 
solidarity and community capacity for collaborative action". One theory that encompasses adolescent pregnancy issues related to social justice is Rawls Theory of Social Justice. This theory provides a framework to explain the significance of political and personal liberties, of equal opportunities, and cooperative arrangement that benefit both the more and the less advantaged members of society (Garrett, 2005, Rawls, 1971). According to Rawls, social justice incorporates two moral powers: a sense of justice and a conception of good.

The sense of justice is to understand, apply, and act from a fair sense of cooperation. Each person has equal rights to equal basic liberties including the right to hold and have exclusive use of personal property. One can then own the means of producing and acquiring natural resources (Garrett, 2005). The underlying principle of the theory for this study is the ability of the less privileged adolescent mother having a pathway to access resources to enhance her ability to avoid a repeat adolescent pregnancy. The concept of good refers to what is valuable in human life. Attachment, loyalties to various groups and associations, ideals of friendships, familial and associational relationships are integral concepts of his theory (Garrett, 2005). As Handwerker (1990) alluded, social relationships are not static and must be managed. Adolescents, therefore, need assistance in managing these social relations to realize goals geared toward adulthood in terms of educational and employment opportunities to break the cycle of repeated pregnancies whether in the adolescent years or beyond. Notwithstanding, the adolescent male parent has an equal responsibility in the prevention of a repeat adolescent pregnancy. Rozie-Battle (2003) urged practitioners and policy makers to institute programs inclusive of adolescent males to address issues of child 
support, paternity, educational, and employment opportunities. Since these social, political, economic, and moral issues are not isolated but exist in a continual mix, all avenues must be considered in the life of the pregnant adolescent to prevent a repeat adolescent pregnancy.

Social justice influences access to affordable health care especially for low income households in the society (West, 2007). Therefore, institutions within the society need to provide for every individual a healthy life and life span (relative to the wealth and technological capability of the society); personal security against violence; the respect of self and others; the ability to form and to benefit from attachments to others, particularly in childhood; autonomy with respect to decisions affecting one's own future and reasoning abilities (West, 2007). The foundations of family resilience, culture, social justice, and political economy all contribute to a conceptualization of how an adolescent mother prevents a repeat adolescent pregnancy.

\section{Summary}

The sexual behaviors of adolescents in the United States continue to result in thousands of unplanned first and repeat pregnancies each year. Many adolescents succumb to the influences around them and become pregnant again during the adolescent period. Yet others are able to draw on their internal resilience and prevent a repeat adolescent pregnancy and rebound to achieve positive adult goals. Resilience and social influences are important concepts in addressing adolescent mothers' prevention of a repeat adolescent pregnancy. Yet, when literature searches were conducted via MEDLINE, CINAHL, and PsycINFO among others, no current study was found that 
specifically addressed these major variables in the adolescent mother's prevention of a repeat pregnancy. One study (Cruz, 2012) investigated the pregnant Latinas' protective factors to prevent a pregnancy, but there was no focus on repeat pregnancies. House (2002) looked at Black adolescents and their social and environmental stressors. Again, there was no focus on adolescent repeat pregnancies. This study is vitally important in addressing how resilience and social influences will have an impact on first time and repeat adolescents preventing a repeat pregnancy. While it may be difficult for many adolescent girls to break the cycle of repeated adolescent pregnancies, with positive social connections and internal resilience, it is possible for adolescent mothers to prevent a repeat adolescent pregnancy. 


\section{CHAPTER III}

\section{METHOD}

This chapter examines the research methodology for this study on the effects of resilience and social influences on adolescent mothers preventing another adolescent pregnancy. The quantitative research design including sample inclusions and exclusion criteria and instrumentation is outlined. Data collection procedures of study site entrée and participant recruitment are reviewed. Data management and data analysis strategies are outlined.

\section{Research Design}

A non-experimental, quantitative cross sectional survey design was used to assess individual resilience and social influences in preventing a repeat pregnancy in a sample of Black and Hispanic adolescent mothers. Black and Hispanic first time and repeat parenting adolescents completed questionnaires on resilience and social influences on abstinence and contraceptive use (rebound) to prevent a repeat pregnancy (recoil). A quantitative design was chosen since the variables of interest could easily be measured with existing instruments (Harwell, 2011).

In this study on the phenomenon of adolescent pregnancy, the variables were easily quantified and transformed into nominal, ordinal, interval, or ratio level data. A survey comparative design was selected as the best method to examine the interactions and effects of the independent variables on the outcome variable of preventing another adolescent pregnancy. 
Additional data were generated from the written reports of a subset of the sample to provide valuable insights insight into key concepts on the theory on resilience and social influences. Written responses were obtained from participants throughout the study who volunteered to answer two open ended questions on their perceptions and experiences of pregnancy, labor, and mothering in the immediate postpartum period.

\section{Research Population}

The study was conducted in Miami Dade, Florida, which registered 3,073 adolescent births in 2007 (Florida Office of Economic and Development Research, 2010). Adolescent mothers who had delivered a viable baby were recruited from three hospitals of a hospital system in Florida. This tertiary hospital system with 3,092 beds is the largest health system in South Florida (Miami Hospitals, 2009). The main campus has approximately 4,200 births yearly, and two satellite hospitals have 1,200 births yearly in each hospital. Thirty percent of deliveries are from adolescent mothers (J. Robinson, personal communication, April 18, 2011). The racial/ethnic distribution of deliveries at this hospital system is approximately $60 \%$ Hispanic (i.e., reflective of Miami Dade's population), 25\% Black, and 15\% White (J. Robinson, personal communication, April 18, 2011). Letters of access obtained from nursing directors of the Women's Hospital Center at each hospital authorizing permission for access to the adolescent populations at the hospital centers are included in Appendix 1. 


\section{Sample}

Using G*Power 3.1 to determine the power of the statistical tests to be used in this study (Faul, Erdfelder, Lang, \& Buchner, 2009), an a priori power analysis showed that for t-tests, a sample size of 128 participants was needed for a power of 0.80 , a medium effect size of 0.50 , and an alpha set at 0.05 . A sample of 107 was required for $F$ tests with multiple regression with two predictor variables (resilience and social influences) yielding a medium effect size of 0.15 , an alpha at 0.05 , and a power of 0.95 . These effects held when the five covariates were added to the equation with similar effect size, alpha, and power.

Nonprobability sampling was conducted from newly delivered adolescents on the hospital system's postpartum units. This time point for data collection was selected as many adolescent mothers are acutely interested in measures to prevent a repeat pregnancy including contraceptive use in the immediate postpartum, as well as many of these mothers do not have continuity of care once they leave the hospital, hence their desire for birth control prior to leaving the hospital (Wilson, Samandari, Koo, \& Tucker, 2011). The sample composed of one gender (i.e., female) and two self-identified racial/ethnic groups (i.e. Black [Afro-Caribbean and African American] and Hispanic). Eligible adolescents had delivered a live infant within 1 to 2 days of being recruited for the study. The desired sample size was 140 in anticipation of possible incomplete or unusable instruments.

Inclusion criteria were Black or Hispanic adolescents girls ages 10-19 years; delivery of a single live healthy, full term infant within 1 to 2 days of birth; being the major care taker of the infant; and able to read English or Spanish at a $5^{\text {th }}$ grade level. 
Since the focus of this study was to determine the effects of resilience and social influences on vulnerable minority adolescent populations, White adolescents were not included in this study at this time. Further exclusions were adolescents who were not the major care giver for their babies, those with complex medical conditions including cardiac, respiratory, metabolic, or mental illnesses, or who delivered infants with congenital anomalies or other medical conditions. In addition, adolescents who were married or living with a romantic partner were excluded. These exclusions limited confounding variables as well as created greater homogeneity of the sample.

All eligible adolescents were approached until the desired sample size was obtained. Every effort was made to recruit equal numbers of Black and Hispanic adolescents to reduce sampling bias. However, there were more eligible Black participants than Hispanics when an adequate sample was obtained. Nevertheless, nonprobability sampling bias was reduced as the adolescent mothers were recruited from more than one hospital location in Miami-Dade County.

\section{Instruments}

\section{Wagnild and Young Resilience Scale (RS)}

Resilience was measured using the Wagnild and Young Resilience Scale (RS).

Developed in 1993, the RS is a 25- item scale that measures the internal resources of an individual and how he/she copes with difficult life events (Wagnild, 2003). The items constructed on a 7-point Likert-type scale from 1 (disagree) to 7 (agree) with a score range of 25 to 175. Higher scores indicate higher resilience (Wagnild \& Young, 1993). From the original study, reliability was estimated with an alpha of .91 . Validity was supported with positive correlation with the Life Satisfaction Index A Scale and the 
Philadelphia Geriatric Center Morale Scale $(r=.30$ and $r=.28, p<.001)$. A negative correlation was found between the RS and the Beck Depression Inventory $(r=-.37, p$ $<.001$ ) (Wagnild \& Young, 1993). The Spanish version of the RS had a Cronbach's alpha of .93 in a previous study (Heilemann, Lee, \& Kury, 2003). The RS was administered in both English and Spanish. Participants were asked to select a Spanish version or an English version.

\section{Adolescent Social Influence Scale (ASIS)}

Social influences were measured using the Adolescent Social Influence Scale (ASIS). The Adolescent Social Influence Scale is an 11 point Likert-type item questionnaire in both English and Spanish developed by Babington, et al. (2007) to assess social influences on Dominican adolescents living in the United States and in the Dominican Republic. Adolescents rate the influence of parents, family, peers, school, and church. The father of the baby was added to the scale as an additional social influence. The scale ranged from 0 (no influence) to 10 (very strong influence) with a score rage of 0 to 60 . The scale was developed for a broader study that explored self-esteem and a wide range of risk behaviors in adolescents (Babington et al., 2007). The reliability estimate was .78 with initial use of this instrument.

\section{Demographic and Clinical Questionnaire}

An investigator developed Demographic and Clinical Questionnaire was used to document the adolescent mothers' age, race, length of labor, socioeconomic status, and education. Contraception and abstinence were measured by an investigator developed questionnaire with participants identifying 
they planned to remain abstinent or would use contraception upon discharge from the hospital. A yes or no answer was required for abstinence or contraceptive use. If the adolescent indicated that she planned to use contraception then she could select her choice of contraceptive from the provided list of birth control options. A subset of the sample volunteered and wrote about their perceptions of their labor, delivery, and postpartum experiences.

\section{Data Collection Protocol}

Data collection was started once approval of the research protocol was secured from the University Office of Research Integrity and the collaborating hospital. Intensive training was conducted with the qualified research assistant (RA). A RA who was fluent in English and Spanish was selected from among graduate nursing students at the university. The student signed a privacy disclosure to maintain the confidentiality of the participants and keep all study materials within the secured confines of the study office. Intensive RA training included orientation to the study's purpose and aims, design, and data collection protocols. The RA became familiar with the study instruments and practiced data collection techniques through role play with the Principal Investigator. After two (one to two hours) team meetings where questions are answered and practice sessions were conducted, the RA was deemed prepared to recruit participants and administer the surveys. However, due to delays in obtaining permission from the collaborating hospital, the RA was unable to participate in data collection.

Participants were recruited from the postpartum units of the three hospitals by the principal investigator (PI). First, the PI met with directors of nursing and 
staff at each of the three hospitals. The study and its importance were discussed at staff meetings to orient nurses and unit staff. Questions were answered. Subject recruitment posters were placed on the postpartum units to encourage potential participants to volunteer for the study and as reminders for nurses and staff members. Handouts were distributed at the ante partum clinics to inform adolescents about the study to encourage their participation during the postpartum period.

The PI visited or called the postpartum units daily to identify potential participants and screen for eligibility. Letters were left with the adolescents for their parents or legal guardians and the adolescent mother to become more familiar with the intent and purpose of the study. Children were involved in this study; therefore, informed consent was procured by the PI from parents or legal guardians, and assent was obtained from adolescents on the postpartum units one to two days after they have delivered. If the parent or guardian was present when the adolescent was approached while on the postpartum unit, then the study was explained to the parent or guardian and a written consent obtained from the parent and a written assent from the adolescent prior to data collection. If the parent or guardian was not present when the adolescent was approached, the PI made contact via telephone with the parent or guardian. The study was explained to the parent or guardian and the PI arranged a time and met with the parent or guardian at the adolescent's bedside to obtain a written parental consent and a written child assent prior to administration of the research instruments. Participants and their parent or legal guardian were informed that the study packet could be completed 
in 50 minutes however they could take as long as they needed to complete the questionnaires. The adolescents were also informed that their participation in the study was voluntary; they could withdraw from the study at any time with no loss of service from the hospital or negative repercussions from Florida International University.

According to Florida Network of Youth and Family Services (2009), being pregnant or having a baby does not emancipate a minor in the state of Florida; therefore, parental or guardian consent was needed prior to enrolling any participant who is less than 18 years old in the study. Thus, 18 and 19 year-olds signed their consents. However, if the adolescent was less than 18 years old and was enrolled in the armed forces or was considered emancipated by a court order, then she signed her own consent to be a participant in the study.

At data collection (i.e., 1 to 2 days after delivery), participants completed a self-administered paper and pencil study packet given by the PI. The adolescent and parent or guardian if indicated were introduced to the study packet which included the demographic data form, another form for the participant to indicate if they choose to remain abstinent after discharge from the hospital or if they plan to use birth control and if so, to indicate from the list given the type of contraceptive that they plan to use. They were then introduced to the two quantitative instruments, the 25-item Resilience Scale and the 6-item Adolescent Social Influence Scale. The adolescents were made aware that they could choose not to answer any question that made them uncomfortable. They were informed that their completed packets would be kept confidential in a locked office with access 
only by the study team. The adolescent mothers received a gift certificate of $\$ 20$ on completion of the questionnaires. The participants were informed that they could have a copy of the results if they so desired once the study was completed and the results were published.

In addition to completing the quantitative instruments, a subset of the sample, approximately $10 \%$ (12 participants) were asked to describe their labor and delivery experiences and to recount how they were supported during labor, delivery, and the immediate postpartum period. Six Blacks and six Hispanic adolescent mothers on the postpartum units participated in writing about their experiences. The mothers were asked to write their responses on paper, however long or short they wanted their answers to be. They were told to take as long as they need to complete their answers. All completed instruments and responses to open ended questions were stored in sealed envelopes and placed in a locked box with access only by the study team.

\section{Data Management}

Using IBM SPSS V20.0., data were entered directly by case. Data cleaning procedures included comparing descriptive variables on random cases to ensure similarity on all variables. Frequency distributions with superimposed histograms were run for all items, subscales, and scales to detect missing data and data entry errors as well as to check for normality.

Every effort was made to identify patterns and amount of missing data. It is important to address missing data as sample size can be significantly reduced with a negative impact on future analyses (Mertler \& Vannatta, 2005; Meyers, Gamst, \& 
Guarino, 2006). An examination of the data set was conducted to determine if any data were missing. No missing data were identified. As previously indicated, a sample of 128 was required by power analysis. In order to prevent the loss of power from missing data, the sample size was extended to 140 participants, however; physical examination of the survey items revealed that each response was complete. Therefore sampling was concluded after 133 participants had completed the survey.

Another possible cause of erroneous results on statistical tests is the presence of outliers. Plots and frequency distribution graphs can provide information on the nature of the outlier, if due to an error, or if that subject is not from that population or the subject is different from the rest of the sample (Mertler \& Vannatta, 2005). Outliers were screened, identified, and managed as needed. Frequency distributions for the categorical variables indicated minimum and maximum values that were all within range for each variable. However, the maximum value for one item on the Resilience Scale was outside the normal range of 1 to 7 . The data set was examined and the only outlier was the item "I make myself do things" with a value of 67 which was identified and corrected.

Variables were re-coded as needed. Of note, there were groups with less than 10 cases in the "Education" and "Income" variables. Grades six or less, seven and eight had only five, three, and eight cases respectively. They were subsequently grouped together as "less than high school" now with sixteen cases. There were eight respondents with a family income of $\$ 20,000-\$ 39,000$ and two who had $\$ 40,000$ or more. The income variable was re-coded with one group with earning under $\$ 20,000$ and another group earning $\$ 20,000$ or more. To meet the requirement for logistic regression with adequate 
numbers of cases in each group, these variables were re-coded so that each group had 10 or more cases.

Measures of central tendency and variability were determined for all continuous variables, including mean, standard deviation, skewness, and kurtosis. Histograms with normal curves were computed for the continuous variables. Inspection of the shape of the histogram revealed a right skewness for the sample's age and fairly normal distributions (skewness and kurtosis) for the English and Spanish Social Influences scales. The English and Spanish Resilience scales were skewed to the right indicating greater responses of higher scores.

\section{Data Analysis}

1. What is the difference in resilience scores between Black and Hispanic parenting adolescent mothers? Independent t-tests were used to test group differences.

2. What is the difference in social influences scores between Black and Hispanic parenting adolescent mothers? Independent t-tests were used to test group differences.

3. What is the relationship and effect between resilience and preventing a repeat adolescent pregnancy (contraceptive use or abstinence) for Black and Hispanic parenting adolescent mothers? Point biserial correlation was used to determine relationships among the variables. Logistic regression was used to analyze the effects of the independent demographic and clinical variables on the outcome variable of preventing a repeat adolescent pregnancy. 
4. What is the relationship and effect between social influences and preventing a repeat adolescent pregnancy (contraceptive use or abstinence) for Black and Hispanic parenting adolescent mothers? Point biserial correlation was used to determine relationships among the variables. Point biserial correlations were used as the outcome variable of preventing a repeat pregnancy (contraceptive use or abstinence) was dichotomous. Logistic regression was used to analyze the effects of the independent variables on the outcome variable of preventing a repeat adolescent pregnancy. Logistic regressions were used as the outcome variable of preventing a repeat pregnancy (contraceptive use or abstinence) was dichotomous.

5. What is the effect of mother's age, race, socioeconomic status, education, and length of labor, resilience, and social influences on preventing a repeat adolescent pregnancy (contraceptive use or abstinence) for Black and Hispanic parenting adolescent mothers? Logistic regression was used to analyze if these effects held while controlling for these specific variables by hierarchical entry of the variables into the model.

\section{Summary}

This study investigated the effects of resilience and social influences on parenting Black and Hispanic adolescent females' contraceptive use or abstinence to prevent a repeat adolescent pregnancy. The quantitative design provided empirical data to guide clinical solutions to reduce this costly problem of repeat adolescent pregnancies. The supplemental responses to the open ended questions generated rich insights into the adolescent mother's perceptions of her labor, delivery, and postpartum experiences, 
thereby enhancing interpretations of her resilience and social influences. Further interventional research can be built upon the findings of this study to prevent or reduce the alarming rates of adolescent pregnancies especially as the United States continue to have the highest proportion of adolescent pregnancies among the developed world. 


\section{CHAPTER IV}

\section{RESULTS}

The focus of this chapter is the data analysis of the findings of this study. Descriptive statistical computations will be reviewed. Inferential statistics will be discussed relevant to each research hypothesis. A summary of self-reports obtained through open ended questions from a subset of the participants with respect to their labor and delivery and postpartum experiences is subsequently presented.

\section{Sample Characteristics}

As identified in Table 1, the sample was composed of 133 participants, with 77 reporting their race/ethnicity as Black and 56 reporting their race/ethnicity as Hispanic. The youngest of this sample was aged 14 years and the oldest was aged 19 years yielding a mean age of 17.8 years. There were two fourteen year olds and 57 nineteen year olds. The 15 to 18 year olds comprised approximately $55 \%$ of the sample. The majority of respondents reported an annual personal or family income of $\$ 20,000$ or less. More than $50 \%$ of the sample had completed high school with $30 \%$ indicating some form of education beyond high school.

Approximately half of the sample had less than 10 hours of labor; about $40 \%$ reported their labor was more than 10 hours. To avoid another pregnancy, $85 \%$ of the participants plan to use contraceptives and $23 \%$ plan to remain abstinent. Given that several participants planned to remain abstinent, yet have some contraception on hand as needed, the percentile exceeded $100 \%$. There were a few participants who planned neither abstinence nor contraceptive use $(\mathrm{N}=4$, 
$3 \%$ ). The most common choice for birth control was the DMPA injection, followed by birth control pills. Of the adolescents in the study, $21 \%$ chose the IUD as their method of birth control (see Table 1).

Table 1

Demographic Distribution of Black and Hispanic Adolescent Mothers

Characteristic
Race/ethnicity

Black

Hispanic
$\mathrm{N}$

77

56

Age

$14-15$

$16-17$

18

19
8

34

34

57

16

21

17

25

25

29

17

5
57.9

42.1

Percentage (\%)

6.0

25.6

25.6

42.8

$$
\underline{\mathrm{M}}=17.8(\mathrm{SD}=1.27)
$$

Education

$<$ High school

12.0

$9^{\text {th }}$

15.8

$10^{\text {th }}$

12.8

$11^{\text {th }}$

18.8

$12^{\text {th }}$

$>$ High school

18.8

21.8 
Income

Under $\$ 20,000$

$\$ 20,000$ or more
123

10
92.5

7.5

Demographic Distribution of Black and Hispanic Adolescent Mothers (cont'd)

Characteristic

Length of Labor

Under 10 hours

10 hours

More than 10 hours
63

14

56

31

102

Contraceptive use

Yes

113

20

No

Choice of Birth Control

None

20

32

40

28

7

6
76.7

85.0

47.4

10.5

42.1

15.0
Pills

Injection

Implant

Other 2

7

0

24.1

30.1

21.1

5.3

4.5 


\section{Results Related to Study Instruments}

\section{Resilience Scale}

The 25-item Resilience Scale and the Spanish version of the Resilience Scale were used to test resilience. This scale has a 7-point Likert score. All statements were positively worded. Scores range from 25 to 175 with higher scores indicating greater resilience. For this sample, the English Resilience Scale had a wider range of scores (57-175) than the Spanish version of the scale (65174). The English Resilience Scale mean score was also higher than the Spanish Resilience Scale mean score (see Table 2).

Table 2

Resilience Scales Scores for Black and Hispanic Adolescent Mothers

\begin{tabular}{lcccc}
\hline Respondents & $\mathrm{n}$ & Range & Mean & SD \\
\hline English Scale & 77 & $57-175$ & 145.8 & 21.59 \\
Spanish Scale & 56 & $65-174$ & 142.1 & 20.79
\end{tabular}

Scores for the resilience scales ranged from 1("strongly disagree") to 7 ("strongly agree"). There were 13 items with a mean score of 6.0 or above on the English Resilience Scale. Some of these higher scoring items were: "I usually manage one way or another" "I am determined", "I have self-discipline' and "I have enough energy to do what I have to do. Another 11 items had a mean score of 5.0 to 5.8. Examples of these were "When I make plans, I usually follow through with them" and, "I can get through difficult times because I have experienced difficulty before" One item "I seldom wonder what the point of it all is" had the lowest mean score. 
The Spanish Resilience Scale had scores of less than five for two items: "I seldom wonder what the point of it all is" and "Sometimes I make myself do things whether I want to or not". Fifteen items had scores of 5.0 to 5.9 . These items included "I usually manage one way or another' and "I feel that I can handle many things at a time" Among the eight highest scoring items were "I can be on my own if I have to" and "I am friends with myself"

\section{Reliability Estimates for the Resilience Scales}

In this study, reliability estimates were conducted for the English and the Spanish Resilience Scales. The Cronbach's alpha for the English Resilience Scale for this sample was similar to previous studies. Likewise, the Spanish Resilience Scale had an alpha that was similar to previous use of the scale (see Table 3).

Table 3

Reliability Estimates for the Resilience Scales

\begin{tabular}{cc}
\hline Scale & Cronbach's alpha \\
\hline Resilience Scale (English) & .90 \\
Resilience Scale (Spanish) & .92
\end{tabular}

\section{Social Influence Scale}

Social influence was measured with the Social Influence Scale. This is a 11-point Likert type scale. Scores ranged from 0 (no influence) to 10 (strong influence) yielding a total score of 60 . This is the first time this scale is used with Black adolescents. The "father of the baby" item is being used for the first time as 
well. The mean score of the present sample for the Social Influence Scale was a moderate value of 35.7 (see Table 4). When examined by race/ethnicity, social influence scores varied for Black and Hispanic respondents. Scores were higher for Black mothers than Hispanic mothers (see Table 4).

Table 4

Social Influence Scale Scores for Black and Hispanic Adolescent Mothers

\begin{tabular}{lllll}
\hline Scale & $\mathrm{N}$ & Range & Mean & SD \\
\hline Overall ASIS score & 133 & $0-60$ & 35.71 & 13.66 \\
Black & 77 & $0-60$ & 36.82 & 12.82 \\
Hispanic & 56 & $0-60$ & 34.18 & 14.6
\end{tabular}

The most significant social influence for the sample was the parents, then the father of the baby (see Table 5). Parents were twice the degree of influence compared to friends for the parenting adolescent mother. Overall, school had the least influence on this sample of adolescent mothers. Similarly, in the original study, parents were the more influential than friends in keeping with these findings (Babington et al., 2007). 
Table 5

Social Influence Overall Item Analysis for Black and Hispanic Adolescent Mothers $(\mathrm{N}=133)$

\begin{tabular}{lcc}
\hline Social Influence & Mean & SD \\
\hline Parents & 8.2 & 2.97 \\
Father of baby & 7.4 & 3.50 \\
Family & 7.1 & 3.22 \\
Church & 5.1 & 4.02 \\
Friends & 4.1 & 3.26 \\
School & 3.9 & 3.98
\end{tabular}

The mean social influence scores varied for Black and Hispanic mothers; therefore each item of the ASIS was examined for degree of influence for each racial/ethnic group (Table 6). Both groups were most influenced by their parents. The family had the second highest influence on the Black mothers while the father of the baby was the second most influential group for the Hispanic adolescents in this sample. Both groups indicated that the church was their third most influential factor. There were differences between the Black and Hispanic mothers on their least influential group. Hispanic adolescent mothers reported that the influence of friends was least important while school was the least of all the influences for Black mothers in this sample. 
Table 6

Hispanic and Black Adolescent Mothers' Social Influence Scores

\begin{tabular}{lcc}
\hline & $\begin{array}{r}\text { Black }(\underline{\mathrm{n}}=77) \\
\text { Mean }(\mathrm{SD})\end{array}$ & $\begin{array}{c}\text { Hispanic }(\underline{\mathrm{n}}=56) \\
\text { Mean }(\mathrm{SD})\end{array}$ \\
\hline Parents & $8.16(3.16)$ & $8.20(2.71)$ \\
Family & $7.27(3.30)$ & $6.89(3.13)$ \\
Father of baby $7.03(3.67)$ & $7.91(3.19)$ \\
Church & $5.58(4.08)$ & $4.43(3.89)$ \\
School & $4.21(3.94)$ & $3.39(4.03)$ \\
Friends & $4.57(3.27)$ & $3.36(3.15)$
\end{tabular}

\section{Reliability Estimate for the Social Influence Scale}

Reliability estimate was conducted for the Social Influence Scale (see

Table 7). This scale was used for the first time with a Black adolescent sample.

The father of the baby was added for the first time as an influence on the adolescent mother. Cronbach's alpha was fairly similar to previous use of this scale. 
Table 7

Reliability Estimates for the Social Influence Scale

\begin{tabular}{cc}
\hline Scale & Cronbach's alpha \\
\hline Social Influence Scale & .72
\end{tabular}

There were no negative values in the inter-item correlation matrices for the scale indicating that the same underlying characteristic was being measured by each item (Pallant, 2010). Of all the items of the scale, parents and family had the strongest correlations. Church, family, parents and school had fairly strong correlations as well (see Table 8).

Table 8

Social Influences Scale Inter-item Correlation Matrix

\begin{tabular}{lccccc}
\hline Parents & Family & \multicolumn{1}{c}{ Friends } & School & Church & Father of Baby \\
\hline Parents 1.000 & .639 & .213 & .332 & .470 & .262 \\
Family .639 & 1.000 & .384 & .295 & .512 & .199 \\
Friends .213 & .384 & 1.000 & .299 & .279 & .023 \\
School .332 & .295 & .299 & 1.000 & .420 & .147 \\
Church .470 & .512 & .279 & .420 & 1.000 & .182 \\
Father .262 & .199 & .023 & .147 & .182 & 1.000
\end{tabular}

Only one item of the Social Influences Scale, "Father of the baby" if deleted would increase the Cronbach's Alpha of the scale (see Table 9). The father of the baby was one the highest influences for the Hispanic mothers in this study. 
Table 9

Social Influences Scale Item-Total Statistics

\begin{tabular}{lc}
\hline Item & Cronbach's Alpha if Item Deleted \\
\hline Parents & .654 \\
Family & .640 \\
Friends & .715 \\
School & .690 \\
Church & .647 \\
Father of baby & .750
\end{tabular}

\section{Research Questions and Related Hypotheses Testing}

The research questions were explored to determine if there were differences in resilience and social influences between Black and Hispanic adolescent mothers, if there were any differences in the effects of resilience and social influences on first time and repeat parenting adolescent mothers preventing another adolescent pregnancy, and if the effects held when several demographic variables are held constant. Inferential statistical procedures including t-tests, correlations, and logistic regressions which included one hierarchical logistic regression were conducted to test the hypotheses relevant to the research questions.

Research Question \# 1 What is the difference in resilience scores between Black and Hispanic parenting adolescent mothers? 


\section{Hypothesis 1: Black and Hispanic parenting adolescent mothers are different}

in their resilience scores.

An independent sample t-test compared resilience scores between Black and Hispanic. Equal variance was assumed on Levene's test for equality of variance $(\mathrm{p}=.68)$. There were no significant differences in scores for Black $(\mathrm{M}=145.8$, $\mathrm{SD}=21.59)$ and Hispanic $(\mathrm{M}=142.09, \mathrm{SD}=20.79)$ mothers, $(\mathrm{t}=.32),(\mathrm{p}=.32)$. ( $\alpha$ set at .05). These findings fail to support Hypothesis 1 , thus the null hypothesis was supported that Black and Hispanic parenting adolescent mothers have similar resilience scores.

Research Question \# 2 What is the difference in social influences scores between Black and Hispanic parenting adolescent mothers?

\section{Hypothesis 2: Black and Hispanic parenting adolescent mothers are different in their social influences scores.}

Using independent t-test, the social influence scores for Blacks and Hispanic parenting adolescents were assessed. Equal variance was assumed on Levene's test for equality of variance $(\mathrm{p}=.14)$. No significant differences were found for Blacks $(\mathrm{M}=36.9, \mathrm{SD}=12.82)$ and Hispanic $(\mathrm{M}=34.2, \mathrm{SD}=14.66)$ mothers, $(\mathrm{t}$ $=.26),(\mathrm{p}=.26)$. The research hypothesis was therefore rejected. The null hypothesis was supported that Black and Hispanic parenting adolescent mothers have similar social influence scores. 
Research Question \# 3 What is the relationship and effect between resilience and preventing a repeat adolescent pregnancy (contraceptive use or abstinence) for Black and Hispanic parenting adolescent mothers?

\section{Hypothesis 3: Higher resilience in Black and Hispanic parenting adolescent mothers} will increase the likelihood of preventing a repeat adolescent pregnancy.

Using point-biserial correlation coefficient to assess relationship strength and direction, a significant positive correlation was found between resilience scores for adolescent mothers and their contraceptive use $(r=.263, \mathrm{p}=.002)$. In addition, a correlation was found between Black adolescent mothers and their use of contraception to prevent a repeat pregnancy $(r=.366, \mathrm{p}<.01)($ see Table 10$)$. This was a moderately strong relationship between resilience scores for Black adolescent mothers and their contraceptive use. There was no significant correlation between Black adolescent mothers resilience scores and preventing a repeat pregnancy by remaining abstinent. No significant correlation was found between resilience scores and Hispanic mothers using contraception or remaining abstinent to prevent a repeat pregnancy (see Table 10). These findings partially supported Hypothesis 3 as resilience in Black adolescent mothers did increase the likelihood of her using contraception to prevent a repeat pregnancy. Hypothesis 3 was partially rejected as resilience or social influences did not increase the likelihood of the adolescent mother remaining abstinent to prevent a repeat adolescent pregnancy. 
Table 10

Point-Biserial Correlations between Resilience and Preventing a Repeat

Adolescent Pregnancy (Contraceptive Use or Abstinence)

\begin{tabular}{llccc}
\hline Abstinence & Black Resilience & Hispanic Resilience & Contraception & \\
\hline Black Resilience & -- & & & -.027 \\
Hispanic Resilience & -- & -- & $.366^{* *}$ & \\
.114 & & -- & -- & - \\
Contraception & $.366^{* *}$ & & & - \\
- & & .114 & -- & \\
Abstinence & -.027 & & & \\
- & & & & \\
\end{tabular}

${ }^{* *}$ Correlation significant at the 0.01 level (2-tailed)

Logistic regression was performed to analyze the effects of several the independent variables (age, socioeconomic status, length of labor, education, race, and resilience scores) on the dependent variable of preventing a repeat pregnancy by contraceptive use. The total number of cases was correct, no group had less than 10 cases, and no standard error was greater than 2.0. As depicted in Table 11; the full model was statistically significant, $X^{2}(11, \mathrm{~N}=133)=27.08, \mathrm{p}=.004$. This model accounted for 18 to $32 \%$ of the variance in contraceptive use, correctly classifying $88 \%$ of cases. Race and resilience were the two significant variables, with resilience (odds ratio $=1.03$ ) being the stronger predictor of adolescent mothers using contraception as the method of preventing a repeat adolescent pregnancy. Black mothers were 3.6 times less likely than Hispanic mothers to use 
birth control (odds ratio $=.28$ ) controlling for other factors in the model (see Table $11)$.

\section{Table 11}

Effects of Resilience on Contraceptive Use by Parenting Adolescent Black and Hispanic Mothers

Logistic Regression Coefficients

\begin{tabular}{lccccc}
\hline Ratio & $B$ & Wald & $d f$ & $p$ & Odds \\
\hline Race (Black) & -1.26 & 3.85 & 1 & .05 & .28 \\
Resilience & .03 & 5.85 & 1 & .02 & 1.03 \\
Constant & -4.92 & 1.27 & 1 & .26 & .01
\end{tabular}

When the independent variables were regressed on Black or Hispanic adolescent mothers remaining abstinent to prevent a repeat adolescent pregnancy, the full model was not statistically significant $(\mathrm{p}=.33)$; hence no conclusions could be made.

In summary, the resilience of the Black adolescent parenting adolescent mother was a significant factor on her decision to use birth control. None of the independent variables had an effect on her decision to remain abstinent. In light of these findings, the research hypothesis was partially supported by the significance of resilience in Black adolescent mothers. The research hypothesis however was partly rejected as resilience did not have an effect on Black or Hispanic mothers preventing a repeat pregnancy by remaining abstinent. 
Research Question \# 4 What is the relationship and effect between social influences and preventing a repeat adolescent pregnancy (contraceptive use or abstinence) for Black and Hispanic parenting adolescent mothers?

\section{Hypothesis 4: Higher social influences on Black and Hispanic parenting adolescent} mothers will increase the likelihood of preventing a repeat adolescent pregnancy.

Point biserial correlation coefficient did not identify any statistically significant correlations between abstinence and social influences scores for Black and Hispanic parenting adolescent girls. Black and Hispanic mothers' social influences scores and their use of contraception were not statistically significantly correlated.

Logistic regression analysis did identify a true model of an effect of age, race, socioeconomic level, education, and length of labor and social influences on contraceptive use for this sample, $X^{2}(11, \mathrm{~N}=133)=21.86$. This model explained 15 to $26 \%$ of the variability in adolescent mothers using contraception in this sample.

However, none of the independent variables were statistically significant in contributing to this model suggesting that there is a missing variable. Logistic regression revealed no significant model for the effect of social influences on Black or Hispanic mothers' abstinence to prevent a repeat pregnancy. These findings supported Hypothesis 4 that social influence has an effect on adolescent mother's contraceptive use. However, the significant variable was not identified in the model.

Research Question \# 5 What is the effect of mother's age, race, socioeconomic status, education, length of labor, resilience, and social influences on preventing a 
repeat adolescent pregnancy (contraceptive use or abstinence) for Black and Hispanic parenting adolescent mothers?

Hypothesis 5: Higher resilience and social influences will increase the likelihood of Black and Hispanic parenting adolescent mothers preventing a repeat adolescent pregnancy when the effects of mother's age, race, socioeconomics, education, and length of labor are held constant.

Logistic regression was performed to analyze if the effect of resilience on contraceptive use held while controlling for age, socioeconomic status, length of labor, education, and race by hierarchical entry of the independent variables into the model. Results indicated a significant model for resilience and contraceptive use $X^{2}(10, N=133)=20.98, p=.021$, and correctly classifying $85 \%$ of cases (see Table 12).

Table 12

Effects of Resilience on Contraceptive Use by Parenting Adolescent Mothers when Independent Variables were held Constant Logistic Regression Coefficients

\begin{tabular}{lccccc}
\hline Ratio & $B$ & Wald & $d f$ & $p$ & Odds \\
\hline Race (Black) & -1.26 & 3.85 & 1 & .05 & .28 \\
Resilience & .03 & 5.85 & 1 & .02 & 1.03 \\
Constant & -4.92 & 1.27 & 1 & .26 & .01
\end{tabular}


When the independent variables were held constant, race and resilience were significant variables having an effect on contraceptive use by Black mothers in this sample. Resilience had no effect of contraceptive use by Hispanic adolescent mothers when the socio-demographic and clinical variables were controlled. Hence, the research hypothesis was partially accepted as there were differences in the effects of resilience on Black and Hispanic adolescent mothers' contraceptive use. However, the research hypothesis was partially rejected since social influences had no effect on either abstinence or contraceptive use by Black or Hispanic mothers in this sample when the independent variables of age, socioeconomic status, length of labor, education, and race were controlled.

\section{Findings Related to Open Ended Questions}

Two open ended questions on the adolescent mother's labor and delivery experiences were added to the demographic survey. A subset of the sample (approximately 10\%) was given the opportunity to describe in writing their perceptions of their labor, delivery, and postpartum experiences. These questions were designed to further investigate differences in resilience and social influences for Black and Hispanic parenting adolescent mothers (Research Questions \#1 and \#2). Participants' responses would potentially provide an opportunity to understand adolescent mothers' resilience and social influences. Subjects volunteered to answer the open -ended questions. Six Black and six Hispanic mothers (approximately $10 \%$ of the sample) provided feedback. Participants responded to (1) "Please tell me about your labor and delivery and postpartum 
experience" (see Table 13), and (2) "How were you supported during your labor and delivery and postpartum experience?" (see Table 14).

Table 13

Adolescent Mothers' Responses on Labor, Delivery, and Postpartum Experiences

\begin{tabular}{|c|c|c|}
\hline \multicolumn{3}{|c|}{ Respondents } \\
\hline \multicolumn{2}{|r|}{ Black Mothers } & Hispanic Mothers \\
\hline \multicolumn{2}{|r|}{$(n=6)$} & $(n=6)$ \\
\hline \multirow[t]{5}{*}{ \#1: } & "Labor was good and delivery better. & "Didn't feel pain or \\
\hline & & anything" \\
\hline & "Mother keep me calm." & "Experience scary and \\
\hline & & exciting." \\
\hline & "My doctors was the best." & \\
\hline \multirow[t]{3}{*}{ \#2: } & "It went very well." & "Went well. Postpartum \\
\hline & & workers, food everything went \\
\hline & & well." \\
\hline \multicolumn{2}{|c|}{ \#3: "A little painful due to me being } & "Thank God, my son is \\
\hline \multicolumn{2}{|c|}{ too far along and not able to } & healthy." \\
\hline
\end{tabular}


Adolescent Mothers' Responses on Labor, Delivery, and Postpartum Experiences (cont'd)

\begin{tabular}{cc}
\hline Respondents & \\
\hline Black Mothers & Hispanic Mothers \\
\hline$(\mathrm{n}=6)$ & $(\mathrm{n}=6)$ \\
\hline
\end{tabular}

\#4: “It went well."

"Bit difficult as could not push much."

"Proud of myself when baby in my arms."

\# 5: "My labor hurted."

"Good experience. Enjoy

bonding with baby. Going home tomorrow."

\# 6: "Exciting and scary."

"Great, very kind and helpful."

"What kept me going was

"Experience great." forward to seeing the baby." 
Table 14

Adolescent Mother's Responses on Support during Labor, Delivery and Postpartum

Respondents

Black Mothers

Hispanic Mothers

$(n=6)$

$(n=6)$

\#1 "My doctors, my family, my nurses."

"Baby father, mother. Nurses

really supportive, easy to talk

to."

\#2 "I had plenty of support from the nurses

"My mom and my aunt." and my mother/boyfriend."

\#3 "Nurses had a lot of patience with me."

"Boyfriend, mother: helped

me think positive thoughts

and motivated."

\# 4 "My family, felt really happy."

"Many people. Mom,

boyfriend. Nurses and

doctors were the best."

\# 5 "Nurses helped me with

Father of baby, his mother,

what I should do when having contraction

my cousin. All holding and

supporting me through it."

\#6 “My boyfriend, my family was

"Doctors, nurses, mother, father of

very helpful."

baby." 
In recounting their labor and delivery and postpartum experiences, "painful", "went well" and "scary and exciting" were terms used by the Black participants. When questioned specifically on how they were supported during their experience, two Black participants mentioned only the nurses as their support and only two mentioned the father of the baby as their support. Common responses on who was their support were family, doctors, and nurses.

The Hispanic mothers' comments on their labor and delivery and postpartum experiences included terms such as "labor was not as bad as I thought", "went well", "scary and exciting" and "baby". Five of the Hispanic adolescent mothers reported that the father of the baby was supportive. Family, nurses, and doctors were also listed as support during the labor and delivery experiences of the Hispanic adolescent mother.

The descriptive responses were then categorized. The differences in the Black and the Hispanic responses were compared and contrasted and the following commonalities found: "support of family" and a "scary yet exciting" time. Differences were found between the Black and the Hispanic mothers responses. Black adolescents reflected on the painfulness of the labor and delivery experience while Hispanic adolescents voiced the support that they received from their family and the father of the baby. Roberts and colleagues (2010) argued that the pain of labor may be perceived by some woman as a positive experience. The internal resilience of the adolescent may enable her to endure labor especially as she looks forward to holding and bonding with her baby. The influences of her 
parents, family, and the father of the baby may also have a positive effect on how she copes with labor and delivery. 


\section{CHAPTER V \\ DISCUSSION}

This chapter presents a discussion of the findings of the study. The implications for practice are explored and the limitations of the study are discussed. Finally, recommendations for future research are presented.

\section{Adolescent Pregnancy}

Adolescents have physical, cognitive, and emotional goals to accomplish as they search for their own identities and engage in moral and social interactions during their transition to adulthood (AACA, 2008; Harder, 2002; Hazen, Schlozman\& Beresin, 2008). Many vulnerable adolescent girls, including minority groups such as Blacks (AfroCaribbean and African-American) and Hispanics may succumb to social pressures and engage in high risk behaviors resulting in unplanned adolescent pregnancies (Patsdaughter, Kelley, Babington, \& Dyer, 2005; Ventura \& Hamilton, 2011). Black and Hispanic adolescents (ages 15-19 years) had 60\% of adolescent births in the United States in 2009 (Centers for Disease Control and Prevention [CDC], 2011). Many adolescents, however, are capable of maximizing their internal mechanism of resilience to rebound from the adverse outcome of an unplanned pregnancy and establish behaviors to prevent a repeat adolescent pregnancy.

The purpose of this study was to investigate the effects of resilience and social influences (i.e., relationship with parents, family, peers, father of the baby, church, and school) on abstinence and contraceptive use in preventing a repeat pregnancy among Black and Hispanic parenting adolescent mothers. Age, socioeconomic status, length of labor, education, and race of these adolescent mothers were other important variables in this 
study. The theoretical framework for this study was the Recoil-Rebound Model which addressed the pregnant adolescent's resilience and social influences in recoiling to a repeat adolescent pregnancy or rebounding to prevent a repeat adolescent pregnancy by contraceptive use or by remaining abstinent.

\section{Discussion of the Findings}

The sample size of 133 was considered adequate as the power analysis required 128 participants. The challenge to obtain the full Hispanic sample occurred as most Hispanics delivered in the south of the county and there were many other hospitals for deliveries beside the study site. The Black sample was easily obtained at the northern and main hospital campuses. The sample mean age was 17 years, with ages ranging from 14 to 19 , yet there was a skewed distribution to the right indicating many older than younger adolescents participated in this study.

\section{Country of Origin}

Some of the countries of origin in this study were Haiti, Honduras, Columbia, Nicaragua, United States, Chile, Mexico, and Guatemala indicating a wide sampling of cultural backgrounds for this study. As was pointed out earlier, the socio-cultural/ethnic background and upbringing of the adolescent affect her outlook on life and the decisions that she will make. In applying Bandura's theory, the adolescent mother can have a desire to prevent another pregnancy and can pattern the behaviors of role models in remaining abstinent or using contraceptives. Black and colleagues (2006) found in their study of Black first time adolescent mothers who were mentored by Black women who were previously adolescent mothers themselves and now in college that the control group was 2.5 times more likely to have a second birth than the intervention group. For the Hispanic 
adolescent mother, Middlemiss and McGuigan (2005) highlighted the importance of her family in providing a framework for her decisions. Hispanic adolescents in this study repeatedly reported that family was important during their labor and delivery and postpartum experiences.

\section{Differences in Resilience in Black and Hispanic Adolescent Parenting}

\section{Mothers}

The resilience scores for the adolescent mothers in this study were similar to those in previous studies (Black \& Ford-Gilboe, 2004; Hunter \& Chandler, 1999). Though not statistically significant, Black adolescent mothers had higher resilience mean scores than Hispanic adolescents in this sample. The higher resilience scores appear to be because Black adolescent mothers depended more on themselves when compared to Hispanic adolescents who appear to utilize more external sources for support and decision making. The responses to the openended questions from the participants, albeit only from $10 \%$ of the sample, supported the idea that Black mothers were more internally focused while Hispanic mothers appear more externally focused during this time of adolescent parenting. For example, comments from the Black subgroups were "A little painful due to me being too far along and not able to receive medicine." and "My labor hurted," implied a preoccupation with her personal experience and made no reference to others around her. Conversely, Hispanic adolescent's statements such as "Baby father, mother, nurses really supportive, easy to talk to," and "Boyfriend, mother, helped me think positive thoughts and motivated" indicated an awareness of the external support that she received during her labor and 
delivery experience. These observations add to the empirical data of Black adolescent mothers having higher resilience scores than Hispanic adolescent mothers.

\section{Differences in Social Influences on Black and Hispanic Adolescent Parenting}

\section{Mothers}

Parents were the most important social influence for both Black and Hispanic adolescent mothers in this study. Despite the significant influences of peers that had been widely reported (Harder, 2002), the parenting adolescent mother, both Black and Hispanic in this study identified the strong influences of parents, family, and the father of the baby in decisions to avoid another adolescent pregnancy. Although the race/ethnicity was different for the samples studied, findings from this study were similar to those of Cook and colleagues (2009) that parents exerted a stronger influence than friends on the adolescent.

The significance of support from school personnel or friends at school was not evident in this sample. This was a surprising finding for participants with only $12 \%$ having less than high school education. It would seem as if pursing an education and being influenced by the school system would have been of greater importance for these adolescents. Yet, many may not be directly involved with school at this time of labor and delivery and focus on the newborn, hence the low scores of the influence of the school environment at this time. It is possible that once she is settled in her role as a mother, the need for continued education may arise, and school may become more important to her. As noted earlier, many of the interventions that incorporate school activities in the lives of adolescent mothers proved successful in their avoiding a repeat pregnancy (Amin \& 
Sato, 2004; Key, Gebregziabher, Marsh, \& O’Rouke, 2008; Schaffer et al., 2008; Thomas \& Looney, 2004).

While not as significant as the father of the baby, parents, or family as an influence on the parenting adolescent, church affiliation carried some importance for this sample, more so than the influences of school or peers. Older adolescents develop further moral reasoning and while seeking their independence may revert to some of the cultural traditions of their parents and families (AACA, 2008; Hazen et al., 2008). Faced with the challenges of adolescent birth and parenting, many may seek a spiritual focus as a strategy for coping with the changes of becoming an adolescent mother.

Additionally, the family concepts of Walsh's Family Resilience theory were evident in the family's belief system, their organizational processes, and their communication and problem solving behaviors. Some families, during data collection, mainly the Hispanic families were jovial, supportive, and asking about the adolescent going back to school. Similarly for the Black families, strong extended family networks existed with grandmothers and aunts present with the adolescent (Andrew \& Boyle, 2002). There was support and communication with the Black adolescent, although on several occasions the adolescent was alone on the postpartum unit, even as young as 14 years old. So it was evident that some families' system breakdown, yet others are able to bounce back in the face of the adverse life event of an adolescent pregnancy (Walsh, 2003).

A key source of support and influence for the adolescent mothers in this study was the father of the baby. Next to parents and family influence, the father of the baby was of paramount importance to the adolescent mother in this study. 
The written responses of a subset of participants highlight how present and supportive the father of the baby was for these young mothers especially the Hispanic adolescents. Regardless of their lower academic and employment potential than their non-parenting peers (Klein and the American Academy of Pediatrics Committee on Adolescence, 2005), at the time of labor and birth, and the immediate postpartum, this study emphasized that the role of the supportive father of the baby was vitally important to the adolescent mother as an influence in preventing another pregnancy either by remaining abstinent or using contraception.

\section{Effects of Resilience on Preventing a Repeat Adolescent Pregnancy for Black and Hispanic Parenting Adolescent Mothers}

Resilience was a key factor in contraceptive use by adolescent mothers in the Recoil-Rebound Model (Porter \& Holness, 2011). The adolescent mother has the ability to use her resilience to overcome the barriers to contraceptive use in preventing a repeat pregnancy and rebounding to positive outcomes of finishing school, gaining employment, and becoming a caring mother (Porter \& Holness, 2011). A relationship was found between Black adolescent mothers' resilience and their plan to use contraceptives as their birth control option. This is a significant finding indicating that an adolescent mother who is resilient can have a desire to prevent another pregnancy and possess that inner strength and desire to prevent another pregnancy. This relationship of resilience and contraceptive was not statistically significant for the Hispanic adolescent mother. 
Conversely, on logistic regression, Black adolescent mothers when compared to Hispanic adolescent mothers were 3.6 times less likely to use contraceptives. The Centers for Disease Control Morbidity and Mortality Weekly Reports (CDC, MMWR, 2012) supported this finding that non- Hispanic Blacks adolescents used birth control less than Hispanic or Whites adolescents. While the CDC report focused on pre-pregnancy contraceptive use among adolescents with unintended pregnancies resulting in live births, some of the reasons given for not using birth control may hold true post-delivery, including her partner not wanting to use contraception, trouble getting birth control, or problems with side effects from contraception (CDC, MMWR, 2012).

There was no statistically significant relationship between resilience scores for Black and Hispanic first time and repeat adolescent mothers and their decision to remain abstinent to prevent a repeat adolescent pregnancy. Almost a fourth of the adolescent mothers were interested in remaining abstinent. In keeping with the findings of Santelli and colleagues (2006) who reported that abstinent may fail in actual practice, some adolescent mothers wanted to remain abstinent yet they plan to have contraception on hand if needed. Interested adolescent mothers could benefit from an abstinent curriculum intervention to prevent repeat adolescent pregnancies (Jemmott, Jemmott, \& Fong, 2010).

\section{Effects of Social Influences on Preventing a Repeat Adolescent Pregnancy for Black and Hispanic Parenting Adolescent Mothers}

There were no significant correlations between social influences and Black or Hispanic adolescent mothers' use of contraception or abstinence to prevent a repeat adolescent pregnancy. On logistic regression, results indicated that there may have been a missing variable from the model. A possible significant variable is the adolescent 
mother's gravidity and or parity. In their study on postpartum implant use, Tocce, Sheeder, and Teal (2012) reported that parity was a predictor of repeat adolescent pregnancy. They found that adolescent mothers who had more than one child and had not received the contraceptive implant during the immediate postpartum had an increased likelihood of a repeat pregnancy at 12 months postpartum. Further research is warranted on the effect of the number of pregnancies and births on the adolescent mother's likelihood of remaining abstinent or using contraception to prevent a repeat adolescent pregnancy.

\section{Effects of Resilience and Social Influences on Contraceptive Use or sexual}

\section{Abstinence when Socio-demographic and Clinical Variables are held}

\section{Constant}

Study participants were generally poor with over $90 \%$ with a personal or perceived family income of less than $\$ 20,000$ yearly. As outlined in the discussion on political economy, here is a sample of economically marginalized individuals existing in an environment of disparity. Again, as purported by Gold et al., (2001), there is a need

for resources to be available to ensure the wellbeing of the less than well off members of a society; only then can there be improvements in the population's health including a reduction in adolescent pregnancy. In the social justice process, there is the need for resources and opportunities for these adolescent mothers to recognize their full potential (Garrett, 2005). Interestingly, despite their low socioeconomic status, many of these adolescent mothers in this sample were educated or pursuing education beyond high school. Many verbalized their occupations as beauticians, clerks, or enrolled in technical schools or colleges. 
Another variable, the length of labor was not a significant factor in this study. Nevertheless, it would be interesting to note if augmentation of labor or pain relief by epidural had an impact on the adolescent perception of her labor and her birth control plans after delivery. In the written responses of a subset of the sample to open ended questions, several adolescents remarked on how epidural anesthesia made labor easier to bear and the support of doctors and nurses enhanced their labor experiences. Many women who labor without pain relief vow never to repeat the experience. Undoubtedly, when the laboring client receives pain relief her outlook on her labor and delivery experience improves. Nevertheless, as Roberts and colleagues (2010) pointed out, the pain of labor is different in that it can be celebrated as the pathway for new life. Further empirical research is needed on the adolescent mother's labor experience to determine if there is an impact on her decision to prevent another pregnancy.

In this study, the adolescent mothers' age, socioeconomic status, education, and length of labor had no effect on her decision to prevent a repeat pregnancy by contraceptive use or abstinence. When these socio-demographic and clinical variables were held constant, the resilience of Black adolescents did have an effect on her contraceptive use. Parenting Black adolescent mothers were found to be 3.6 times less likely than Hispanic adolescents to use contraception to prevent a repeat adolescent pregnancy. Outlined in the Recoil-Rebound Model is the resilience of the adolescent to rebound from the adolescent pregnancy and prevent another adolescent pregnancy. The concern now is that one of the most vulnerable groups for a repeat adolescent pregnancy, the black adolescent mother is under-utilizing contraception-an effective method to prevent a repeat adolescent pregnancy (CDC, MMWR, 2012). Clinical strategies need to 
be employed to overcome the barriers to contraceptive use by Black adolescents parenting mothers. No significant effect was found for social influences and the decision to prevent a repeat adolescent pregnancy by contraceptive use or abstinence for the Black or Hispanic adolescent mothers controlling for age, race, education, socioeconomic status, and length of labor.

\section{Resilience and Social Influence Scales}

The scales used in this study had acceptable Cronbach's alphas. The English Resilience Scale $(\alpha=.90)$ and the Spanish Resilience Scale $(\alpha=.92)$ both had alphas which were similar to previous studies (Black and Ford-Gilboe, 2004; Heilemann, Lee, \& Kury, 2003; Hunter \& Chandler, 1999). The reliability estimates of the scales in this study were more than adequate for social sciences research.

The Social Influences Scale was used for the first time with a non-Hispanic sample. Additionally, the "father of the baby" was an added item to the Social Influences Scale, with the alpha being equally adequate. The Cronbach's alpha for the Social Influence Scale (.72) was close to the alpha used in previous studies (.78) (Babington et al., 2007).

\section{Implications for Practice}

Adolescent pregnancy remains a national and international dilemma. Adolescents in the U.S. have the highest pregnancy rates in a developed country (WHO, 2009). This study's findings indicate that race and resilience are key factors in adolescent mothers' use of contraceptive. In improving the reproductive health of minority adolescents, programs and interventions can focus on the internal resilience of Black adolescents to improve contraceptive use as a method of preventing a repeat adolescent pregnancy. 
The resilient adolescent can believe in her capability to take action to manage situations in her life such as coping with an adolescent pregnancy and preventing a repeat adolescent pregnancy (Bandura, 1997). Health care providers are encouraged to incorporate adolescent resilience in strategies for consistent contraceptive use, utilization of more effective birth control, and encouragement of abstinence and delay of sexual activity (CDC, 2012).

In this study, $23 \%$ of the participants plan to remain abstinent as a birth control option; therefore the option of refraining from further sexual activity must be highlighted as a favorable and possible choice for the parenting adolescent mother. Interventions such as classroom curricula promoting abstinence have shown to delay in timing of conception for adolescent. There is limited literature on abstinence as a strategy to prevent a repeat pregnancy for adolescent mothers. The resilient adolescent mother, if equipped with cognitive and behavioral strategies and positive social influences may be able to remain abstinent and thus prevent a repeat pregnancy (Jemmott, Jemmott, \& Fong, 2010).

Nurses in the labor, delivery, and postpartum units were noted to be coaches to laboring and parenting adolescents. The role of the nurse cannot be overemphasized as she guides the adolescent through a "scary yet exciting" experience to become a caring and responsible parenting mother. In the immediate postpartum period, most adolescent mothers are amenable to strategies to prevent a repeat pregnancy (Tocce, Sheeder, \& Teal, 2012). Maternity health care personnel including obstetricians, midwives, nurses, social workers and other involved in improving the reproductive health of adolescents are positioned to make long term impact on the adolescent mother through discussions on abstinence and contraceptive use as avenues to prevent a repeat pregnancy. 
Additionally, promoting parental and family support are key elements for the parenting adolescent. Maternity staff can facilitate the involvement of the father of the baby in the care of the adolescent mother and child in the immediate postpartum thus strengthening emotional bonds (Rozie-Battle, 2003).

\section{Limitations of the Study}

This study had several limitations. The study was conducted in a southern state in the U.S. and thus may lack some generalizability. Some of the groups in the study had small numbers of cases which may affect the results of this study. While every effort was made to obtain equal numbers of Blacks and Hispanic participants, the final sample size had more Blacks than Hispanics. It was a challenge to obtain the Hispanic sample as there were several hospitals beside the study site where Hispanic adolescents delivered. Participants were not asked if they were first time or repeat adolescent mothers. Gravidity and parity possibly could have explained some of the variance in several of the logistic regression models. A few of the self-identified Hispanic clients requested the English version of the Resilience Scale which may skew the reliability estimate for the Spanish version of the instrument as the actual sample size would be less than the total Hispanic sample size. Nevertheless, there were significant findings from this study to make worthwhile contributions in developing strategies to reduce adolescent pregnancy especially in the U.S., the developed country with the highest rates.

\section{Recommendations for Future Research}

Birth control use among inner city Black adolescent mothers need to be further explored, more so with a mixed method study to uncover perceptions and barriers to 
contraceptive use. Further investigation is needed on the country of origin of the adolescent to determine if there are any relationships between race, socio-cultural factors, abstinence, and contraceptive use. Thus, culturally focused evidence based interventions could be developed to address reducing adolescent pregnancy, especially for vulnerable multicultural populations.

A focus study is warranted on the role, attitude, and support of Black and Hispanic adolescent fathers, mothers, and grandparents in the lives of adolescent mothers as these individuals were significant influences in this study. Finally, a longitudinal study with similar variables and varied time points of data collection would provide further information on the adolescent mother's resilience and social influences as she recovers from labor and delivery and rebounds to successful prevention of a repeat adolescent pregnancy.

\section{Conclusion}

The concept of resilience was a key component in this study on preventing a repeat adolescent pregnancy in Black and Hispanic adolescent mothers. There were no significant relationships between resilience and contraceptive use or abstinence to prevent a retreat adolescent pregnancy for Hispanic parenting adolescent mothers. Social influence was a significant predictor of contraceptive use however none of the socio-demographic or clinical variables in this study was found to contribute to this effect. 
Significant statistical findings corroborate the importance of resilience in the lives of parenting adolescent mothers, especially when making decisions on contraceptive use. While resilient Black adolescent mothers will use contraception, they are less likely to use birth control than Hispanic adolescent mothers. Therefore, clinical strategies are needed to optimize resilience in Black adolescent mothers to promote effective methods of preventing repeat adolescent pregnancies. 


\section{REFERENCES}

Ahern, N. R. (2006). Adolescent resilience: An evolutionary concept analysis. Journal of Pediatric Nursing, 21(3), 175-185. doi:10.1016/j.pedn.2005.07.009

Ahern, N. R., Kiehl, E. M., Sole, M. L., \& Byers, J. (2006). A review of instruments measuring resilience. Issues in Comprehensive Pediatric Nursing, 29, 103-125. doi:10.1080/01460860600677643

American Academy of Child and Adolescent's Facts for Families. (2008). Stages of adolescent development. Retrieved from www.ehsnrc.org/publications/English\%20Tip\%20Sheets/TIP20SHEET\%2034 ad dendum.pdf

American Academy of Pediatric Committee on Adolescents. (2007). Contraception and adolescents. Pediatrics, 120 (5), 1135-1148. doi:10.1542/peds.2007-2535

Amin, R., \& Sato, T. (2004). Impact of a school-based comprehensive program for pregnant teens on their contraceptive use, future contraceptive intention, and desire for more children. Journal of Community Health Nursing, 21(1), 39-47. doi:10.1207/s15327655jchn2101_4

Andrews, M. M., \& Boyle, J. S. (2002). Transcultural concepts in nursing care. Philadelphia, PA: Wolters Kluwer/Lippingcott, Williams \& Wilkins.

Aronowitz, T., \& Morrison-Beedy, D. (2004). Comparison of the maternal role in resilience among impoverished and non-impoverished early adolescent African American girls. Adolescent \& Family Health, 3(4), 155-163.

Babington, L. M., Kelley, B. R., \& Patsdaughter, C. A. (2007). Risk behaviors of Dominican adolescents. Journal of Pediatric Health Care, 21(6), 372-380. doi:10.1016/j.pedhc.2007.03.005

Bandura, A. (1982). Self-efficacy mechanism in human agency. American Psychologist, 37(2), 122-147. doi:10.1037/0003-066X.37.2.122

Bandura, A. (1997). Self-efficacy: The exercise of control. New York: Freeman.

Barnet, B., Liu, J., DeVoe, M., Alperovitz-Bichell, K., \& Duggan, A. K. (2007). Home visiting for adolescent mothers: Effects on parenting, maternal life course, and primary care linkage. Annals of Family Medicine, 5, 224 - 232. doi:10.1370/afm.629 
Bersamin, M. M., Fisher, D. A., Walker, S., Hill, D. L., \& Grube, J. W. (2007). Defining virginity and abstinence: Adolescents' interpretations of sexual behaviors. Journal of Adolescent Health, 41, 182-188. doi:10.1016/j.jadohealth.2007.03.011

Bissell, M. (2000). Socio-economic outcomes of teen pregnancy and parenthood: A review of literature. The Canadian Journal of Human Sexuality, 9(3), 191-204.

Black, C. (2004). Adolescent mothers: resilience, family health work and health promoting practices. Journal of Advanced Nursing, 48(4), 351-360. doi:10.1111/j.1365-2648.2004.03204.x

Black, M. M., Bentley, M. E., Papas, M. A., Oberlander, S., Teti, L. O., McNary, S., O'Connell, M. (2006). Delaying second births among adolescent mothers: A randomized, controlled trial of a home-based mentoring program. Pediatrics, 118, 1087-1099. doi:10.1542/peds.2005-2318

Black, C., \& Ford-Gilboe, M. (2004). Adolescent mothers: Resilience, family health work, and health-promoting practices. Journal of Advanced Nursing, 48, 351360. doi:10.1111/j.1365-2648.2004.03204.x

Blank, L., Baxter, S. K., Payne, N., Guillaume, L.R., \& Squires, H. (2012). Systematic review and narrative synthesis of the effectiveness of contraceptive service interventions for young people delivered in health care settings. Health Education and Research, 27(6), 1102-1119. doi:10.1093/her/cys056

Breheny, M., \& Stephens, C. (2004). Barriers to effective contraception and strategies for overcoming them among adolescent mothers. Public Health Nursing, 21 (3), 220-227. doi:10.1111/j.0737-1209.2004.021304.x

Bruckner, H., Martin, A., \& Bearman, P. S. (2004). Ambivalence and pregnancy: Adolescents' attitudes and contraceptive use in pregnancy. Perspectives on Sexual and Reproductive Health, 36(6), 248-257.doi:10.1111/j.19312393.2004.tb00029.x

Burk, M. E., Wieser, P. C., \& Kegan, L. (1995). Cultural beliefs and health behavior of pregnant Mexican-American women: Implications for primary care. Advances in Nursing Science, 17(4), 37-52.

Burt, M. R. (2002). Reasons to invest in adolescents. Journal of Adolescent Health, 31 (suppl.6) 136-152. doi:10.1016/S1054-139X(02)00486-X

Business Dictionary. (2012). Social justice definition. Retrieved from http://www.businessdictionary.com/definition/social-justice.htmlocial justice to deter antisocial behaviors. Journal of Youth and Adolescence, 38, 1240-1252. 
Centers for Diseases Control and Prevention. (2011). NCHS data on teen births in U.S. Retrieved from

http://www.cdc.gov/reproductivehealth/AdolescentReproHealth/index.htm

Centers for Disease Control and Prevention (2012). Pre-pregnancy contraceptive use among teens with unintended pregnancies resulting in live births-Pregnancy risk assessment monitoring system (PRAMS), 2004-2008.MMWR. Morbidity and Mortality Weekly Reports. 61 (20), 25-29. Retrieved from http://www.cdc.gov/mmwr/preview/mmwrhtml/mm6102a1.htm.

Centers for Diseases Control and Prevention. (2013). QuickStats: Rates of pregnancies and pregnancy outcomes among teens aged 15-19 years, by race/ethnicity. Retrieved from http://www.cdc.gov/mmwr/preview/mmwrhtml/mm6248a6.htm?s_cid=mm6248a 6_e

Casey, B. J., Getz, S., \& Galvan, A. (2008). The adolescent brain. Development Review, 28(1), 62-77. doi:10.1016/j.dr.2007.08.003

Connolly, J. \& McIsaac, C. (2008). Adolescent romantic relationships: Beginnings, endings, and psychosocial challenges. International Society for the Study of Behavioural Development Newsletter, 53, 1-5.

Connor, K. M., \& Davidson, R. T. (2003). Development of a new resilience scale: The Connor-Davidson resilience Scale (CD-RISC). Depression and Anxiety, 18, 7682. doi:10.1002/da. 10113

Cook, E. C., Buehler, C., \& Henson, R. (2009). Parents and peers as social influences to deter antisocial behaviors. Journal of Youth and Adolescence, 38, 1240-1252. doi:10.1007/s10964-008-9348-x

Crittenden, C. P., Boris, N. W., Rice, J. C., Taylor, C. A., \& Olds, D. L. (2009). The role of mental health factors, behavioral factors, and past experiences in the prediction of rapid repeat pregnancy in adolescence. Journal of Adolescent Health, 44, 2532. doi:10.1016/j.jadohealth.2008.06.003

Doğan-Ateş, A., \& Carrion-Basham, C. Y. (2007). Teenage pregnancy among Latinas: Examining risk and protective factors. Hispanic Journal of Behavioral Science, 29(4), 554-569. doi:10.1177/0739986307308163

Duckett, R. J. (2009). Black adolescent mothers and their families: A phenomenological study of resilience. (Doctoral dissertation, Seton Hall University). 
Retrieved from

http://domapp01.shu.edu/depts/uc/apps/libraryrepository.nsf/resourceid/DAF9CD D0F592B2AC8525767700592413/\$File/Duckett-Robin-J_Doctorate.pdf?Open

Dyer, J. G., \& McGuiness, T. M. (1996). Resilience: Analysis of the concept. Archives of Psychiatric Nursing, 10(5), 276-282. doi:10.1016/S0883-9417(96)80036-7

El-Kamary, S. S., Higman, S. M., Fuddy, L., McFarlene, E., Sia, C., \& Duggan, A.K. (2004). Hawaii' healthy start home visiting program: Determinants and impact of rapid repeat births. Pediatrics, 114(3), e317-e326. doi:10.1542/peds.2004-0618

Escarce, J. J. (Ed.). (2003). Socioeconomic status and the fates of adolescents. Health Services Research, 38(5) 1229-1234. doi; 10.1111/1475-6773.00173

Faul, F., Erdfelder, E., Lang, A., \& Buchner, A. (2009). Statistical power analysis using 3.1: Tests for correlation and regression analyses. Behavior Research Methods, 41(4), 1149-1160. doi:10.3758/BRM.41.4.1149

Fergus, S., \& Zimmerman, M. A. (2005). Adolescent resilience: A framework for understanding healthy development in the face of risk. Annual Review of Public Health, 26, 399 - 419. doi:10.1146/annurev.publhealth.26.021304.144357

Florida Network of Youth and Family Services. (2009). The legal guide for pregnant teens in Florida. Retrieved from http://www.floridanetwork.org/PDFs\%5CFL_Preg_Parent_ENsearchable. pdf

Florida Office of Economic and Development Research. (2010). Florida Population estimates. Retrieved from http://www.floridacharts.com/FLQuery/Population/PopulationRpt.aspx

Ford, K., Weglicki, L., Kershaw, T., Schram, C., Hoyer, P. J., \& Jacobson, M. L. (2002). Effects of a prenatal care intervention for adolescent mothers on birth weight, repeat pregnancy, and educational outcomes at one year postpartum. Journal of Perinatal Education, 11(1), 35-38.

Frank, R., Cerda, M., \& Rendon, M. (2007). Barrios and burbs: Residential context and health-risk behaviors among Angelino adolescents. Journal of Health and Social Behavior, 48(3), 283-300. doi: 10.1177/002214650704800306

Garrett, J. (2005). Rawls' Mature Theory of Social justice: An introduction for students. Retrieved from http://www.wku.edu/ jan.garrett/ethics/matrawls.htm 
Gee, C., \& Rhodes, J. (2007). A social support and social strain measure for minority adolescent mothers: A confirmatory factor analytic study. Child Care, Health and Development, 34, 87-97. doi:10.1111/j.1365-2214.2007.00754.x

Gibson, S. (2004). Social learning (cognitive) theory and implications for human resources development. Advances in Developing Human Resources, 6(2), 193210.doi:10.1177/1523422304263429

Giger, J. N., \& Davidhizar, R. (2002). The Giger and Davidhizar transcultural assessment model. Journal of Transcultural Nursing, 13(3), 185-188. doi:10.1177/10459602013003004

Gillespie, B. M., Chaboyer, W., \& Wallis, M. (2007). Development of a theoretically driven model of resilience through concept analysis. Contemporary Nurse, 25(12) 124-136. doi: 10.5172/conu.2007.25.1-2.124

Gold, R., Kawachi, I., Kennedy, B. P., Lynch, J. W., \& Connell, F. A. (2001). Ecological analysis of teen birth rates: Association with community income and income inequality. Maternal and Child Health Journal, 5(3), 161-167. doi:10.1023/A:1011343817153

Grigorenko, E. L., Jarvin, L., Kaani, B., Kapungulya, P. P., Kwiatkowski, J., \& Sternberg, R. J. (2007). Risk factors and resilience in the developing world: One of many lessons to learn. Development and Psychopathology, 19(3), 747-765. doi:10.1017/S0954579407000375

Guilamo-Ramos, V., Dittus, P., Jaccard, J., Johansson, M., Bouris, A., \& Acosta, N. (2007). Parenting practices among Dominican and Puerto Rican mothers. Social Work, 52(1), 17-30. doi:10.1093/sw/52.1.17

Gutgesell, M. E., \& Payne, N. (2004). Issues of adolescent psychological development in the 21st century. Pediatrics in Review, 25, 79 - 85. doi: 10.1542/pir.25-3-79

Guttmacher Institute. (2013). Facts on American Teens' Sexual and Reproductive Health. Retrieved from http://www.guttmacher.org/pubs/FB-ATSRH.html

Guttmacher Institute. (2010). U.S. teenage pregnancy statistics: National and state trends by race and ethnicity. Retrieved from http://www.guttmacher.org/pubs/USTPtrends.pdf

Handwerker, W. (Ed.). (1990). Births and powers: Social change and the politics of reproduction. Boulder, $\mathrm{CO}$ : Westview.

Harder, A. (2002). The developmental stages of Erik Erikson. Retrieved from www.learningplaceonline.com/stages/organize/Erikson.htm 
Harwell, M. (2011). Research design in quantitative/quantitative/mixed methods. C. F. Conrad \& R. C. ...... Serlin, (Eds.), The sage handbook for research in education: Pursuing ideas as the keystone of exemplary inquiry, ( $2^{\text {nd }}$ ed.). Thousand Oaks: CA: Sage.

Hawley, D. R., \& DeHaan, L. (1996). Toward a definition of family resilience: Integrating life-span and family perspectives. Family Process, 35(3), 283-298. doi:10.1111/j.1545-5300.1996.00283.x

Hazen, E., Schlozman, S., \& Beresin, E. (2008). Adolescent psychological development: A review. Pediatrics in Review, 29, 161. doi: 10.1542/pir.29-5-161

Healthy People 2020. (2012). Family Planning. Retrieved from http://healthypeople.gov/2020/topicsobjectives2020/overview.aspx?topicid=13

Heilemann, M. V., Lee, K., \& Kury, F. S. (2003). Psychometric properties of the Spanish version of the Resilience Scale. Journal of Nursing Measurement, 11(1), 61-71.

Holness, N. (2009). Dominican teens: A cross-national evaluation of social influences and self-esteem on sexual risk behaviors. (Unpublished doctoral paper). Florida International University, Miami, FL.

Hunter, A. J., \& Chandler, G. E. (1999). Adolescent resilience. Image: Journal of Nursing Scholarship, 31(3), 243-247. doi:10.1111/j.1547-5069.1999.tb00488.x

International Planned Parenthood Federation. (2012). Contraception. Retrieved from http://ippf.org/our-work/what-we-do/Contraception

Jacelon, C. S. (1997). The trait and process of resilience. Journal of Advanced Nursing, 25, 123-129. doi:10.1046/j.1365-2648.1997.1997025123.x

Jemmott, J. B. III, Jemmott, L. S., \& Fong, G. T. (2010). Efficacy of a theory-based abstinent- only intervention over 24 months: A randomized controlled trial with young adults. Archives of Pediatrics and Adolescent Medicine, 164 (2), 152-159.

Johnson, J. L., \& Wiechilt, S. A. (2004). Introduction to the special issue on resilience. Substance Abuse and Misuse, 39(5), 657-670. doi:10.1081/JA-120034010

Katz, R. S., Rodan, M., Milligan, R., Tan, S., Courtney, L., Gantz, M., Blake, S. M. McClain, L., Davis, M., Kiely, M., \& Subramanian, S. (2011). Efficacy of a randomized cell phone-based counseling intervention in postponing subsequent pregnancy among teen mothers. Maternal and Child Health Journal, 1, S42 - S53. doi: 10.1007/s10995-011-0860-3 
Keating-Lefler, R., \& Wilson, M. E. (2004). The experience of becoming a mother for single, unpartnered, Medicaid-eligible, first time mothers. Journal of Nursing Scholarship 36(1), 23-39. doi:10.1111/j.1547-5069.2004.04007.x

Kershaw, T. S., Niccolai, L. M., Ickovics, J. R., Lewis, J. B., Meade, C. S., \& Ethier, K. (2003). Short and long term impact of adolescent pregnancy on postpartum contraceptive use: Implications for prevention of repeat pregnancy. Journal of Adolescent Health, 33, 359-368. doi:10.1016/S1054-139X(03)00138-1

Key, J. D., Barbosa, G. A., \& Owen, V. J. (2001). The Second Chance Club: Repeat adolescent pregnancy prevention with a school-based intervention. Journal of Adolescent Health, 28, 167-169. doi:10.1016/S1054-139X(00)00186-5

Key, J. D., Gebregziabher, M. G., Marsh, L. D., \& O’Rouke, K. M. (2008). Effectiveness of an intensive school-based intervention for teen mothers. Journal of Adolescent Health, 42, 394 - 400. doi:10.1016/j.jadohealth.2007.09.027

Klang, L., \& Fuligini, A. J. (2009). Ethnic identity in context: Variations in ethnic exploration and belonging within parent, same-ethnic peer, and different-ethnic peer relationships. Journal of Youth and Adolescence, 38, 732-743. doi:10.1007/s10964-008-9278-7

Klein, J. D. and the American Academy of Pediatrics Committee on Adolescence. (2005). Adolescent pregnancy: Current trends and issues. Pediatrics, 116(1), 281-286. doi: 10.1542/peds.2005-0999

Kohli, V., \& Nyberg, K. L. (1995). Teen pregnancy prevention through education. Sacramento, CA: Center for California Studies, California State University.

Koniak-Griffin, D., Lesser, J., Uman, G., \& Nyamathi, A. (2003). Teen pregnancy, motherhood, and unprotected sexual activity. Research in Nursing \& Health, 26, 4-19. doi:10.1002/nur.10062

Latka, M. H., Kapadia, F., \& Fortin, P. (2008). The female condom: Effectiveness and convenience, not 'female control' valued by US urban adolescents. AIDS Education and Prevention, 20(2), 160-170. doi:10.1521/aeap.2008.20.2.160

Lewis, L. N., Doherty, D. A., Hickey, M., \& Skinner, S. R. (2010). Implanon as a contraceptive choice for teenage mothers: A comparison of contraceptive choices, acceptability, and repeat pregnancy. Contraception, 81, 421-426. doi:10.1016/j.contraception.2009.12.006 
Manlove, J. S., Terry-Humen, E., Ikramullah, E. N., \& Moore, K. A. (2006). The role of parent religiosity in teens' transition to sex and contraception. Journal of Adolescent Health, 39(4), 578-587. doi:10.1016/j.jadohealth.2006.03.008

Martino, S. C., Elliott, M. N., Collins, R. L., Kanouse, D. E., \& Berry, S. H. ( 2008). Virginity pledgers among the willing: Delays in first intercourse and consistency of condom use. Journal of Adolescent Health, 43, 341-348. doi:10.1016/j.jadohealth.2008.02.018

McNicholas, C., \& Peipert, J. F. (2012). Long-acting reversible contraception for adolescents. Current Opinion in Obstetrics \& Gynecology, 24(5), 293-298. doi:10.1097/GCO.0b013e32835686d5

Meade, C. S., \& Ickovics, J. R. (2005). Systematic review of sexual risk among pregnant and mothering teens in the USA: Pregnancy as a opportunity for integrated prevention of STD and repeat pregnancy. Social Science \& Medicine, 60, 661678. doi:10.1016/j.socscimed.2004.06.015

Meade, C. S., Kershaw, T. S., \& Ickovics, J. R. (2008). The intergenerational cycle of teenage motherhood: An ecological approach. Health Psychology, 27(4), 419429. doi:10.1037/0278-6133.27.4.419

Merriam-Webster Online Dictionary (2009c). Rebound. Retrieved from http://www.merriam-webster.com/dictionary/rebound

Merriam-Webster Online Dictionary (2009d). Recoil. Retrieved from http://www.merriam-webster.com/dictionary/recoil

Mertler, C. A., \& Vannatta, R. A. (2005). Advanced and multivariate statistical methods. (3rd ed.). City, CA: Pyrczak.

Meyers, L. S., Gamst, G, \& Guarino, A. J. (2006). Applied multivariate research: Design and interpretation. Thousand Oaks, CA: Sage.

Miami Hospitals, (2009.) Jackson Hospital System. Retrieved from http://miami.about.com/od/hospitals/a/miami_hospitals.htm

Middlemiss, W., \& McGuigan, W. (2005). Ethnicity and adolescent mothers' benefit from participation in home-visitation services. Family Relations, 54 (2), 212-224. doi:10.111/j.0197-6664.2005.00017.x

Nadeem, E., Romo, L. F., \& Sigman, M. (2006). Knowledge about condoms among lowincome pregnant Latina Adolescents in relation to explicit maternal discussion of contraceptives. Journal of Adolescent Health, 39, 119.e9-119.e15. doi:10.1016/j.jadohealth.2005.09.012 
Omar, H., Fowler, A., \& D’Angelo, S. (2002). Improved continuation rate of DepotMedroxyprogesterone Acetate in adolescent mothers. International Journal of Adolescent Medicine \& Health, 14 (2), 149 - 152.

Omar, H., Fowler, A., \& McClanahan, K. K. (2008). Significant reduction of repeat pregnancy in a comprehensive young parent program. Journal of Pediatric Adolescent Gynecology, 21, 283-287. doi:10.1016/j.jpag.2007.08.003

Pallant, J. (2010). SPSS Survival Manual (4 ${ }^{\text {th }}$ ed.). England: McGraw-Hill.

Patsdaughter, C. A., Kelley, B. R., Babington, L. M., \& Dyer, J. G. (2005). A comparison of sexual risk behaviors of Dominican adolescents in their homeland and in the United States. Journal of Multicultural Nursing \& Health, 11(1), 63-68.

Peterson, R. (1991). Political economy and American capitalism. Norwell, MA: Kluwer Academic.

Peterson, S. J., \& Bredow, T. S (2009). Middle range theories ( $2^{\text {nd }}$ ed.). Philadelphia, PA: Wolters Kluwer Health/Lippincott Williams \& Wilkins.

Perry, R. L., Mannino, B., Hediger, M. L. \& Scholl, T. O. (1996). Pregnancy in early adolescence: Are there obstetric risks? The Journal of Maternal-Fetal Medicine, 5, 333- 339. doi:10.1002/(SICI)1520-6661

Physics Van. (2006). The bouncing ball. Retrieved from http://van.physics.illinois.edu/qa/listing.php?id=101

Polk, L.V. (1997). Toward a middle range theory of resilience. Advances in Nursing Science. 19 (3), 1-13.

Porter, L. (1998). Reducing teenage and unintended pregnancies through client-centered and family-focused school-based family planning programs. Journal of Pediatric Nursing, 13(3), 158-163. doi:10.1016/S0882-5963(98)80074-2

Porter, L. \& Holness, N. (2011). Breaking the repeat teen pregnancy cycle: How nurses can nurture resilience in at-risk teens. Nursing for Women's Health, 15(5), 369381. doi:10.1111/j.1751-486X.2011.01661.X

Raneri, L. G., \& Wiermann, M. (2007). Social ecological predictors of repeat adolescent pregnancy. Perspectives on Sexual and Reproductive Health, 39(1), 39-47. doi: $10.1363 / 3903907$ 
Rashotte, L. (2009). Social Influence. In G. Ritzer \& J. M. Ryan (Eds.), The Concise Blackwell Encyclopedia of Sociology. Oxford, England: Blackwell.

Rawls, J. (1971). A theory of justice. Cambridge, MA: Harvard University Press.

Rew, L., Taylor-Seehafer, M., Thomas, N. Y., \& Yockey, R. D. (2001). Correlates of resilience in homeless adolescents. Journal of Nursing Scholarship, 33 (1), 3340.doi:10.1111/j.1547-5069.2001.00033.x

Rickert, V. I., Tiezzi, L., Lipshutz, J., Leon, J., Vaughan, R. D., \& Westhoff, C. (2007). Depot now: Preventing pregnancies among adolescents and young adults. Journal of Adolescent Health, 40, 22-28. doi:10.1016/j.jadohealth.2006.10.018

Roberts, L., Gulliver, B., Fisher, J., \& Cloyes, K. G. (2010). The coping with labor algorithm: An alternate pain assessment tool for the laboring woman. Journal of Midwifery \& Women's Health, 55 (2), 107-116.

Rosenbaum, J. E. (2009). Patient teenagers: A comparison of the sexual behavior of virginity pledgers and matched nonpledgers. Pediatrics, 123, e110-e120. doi:10.1542/peds.2008-0407

Rosengard, C. (2009). Confronting the intendedness of adolescent rapid repeat pregnancy. Journal of Adolescent Health, 44, 5-6. doi:10.1016/j.jadohealth.2008.10.132

Rozie-Battle, J. (2003). Economic support and the dilemma of teen fathers. Journal of Health and Social Policy, 17(1), 73-86. doi:10.1300/J045v17n01_05

Rutter, M. (1985). Resilience in the face of adversity: Protective factors and resistance to psychiatric disorder. British Journal of Psychiatry, 147, 598-611. doi:10.1192/bjp.147.6

Salihu, H. M., August, E. M., Jeffers, D. F., Mbah, A. K., Alio, A. P., \& Berry, E. (2011). Effectiveness of a Federal Healthy Start program in reducing primary and repeat teen pregnancies: Our experience over a decade. Journal of Pediatric and Adolescent Gynecology, 24 (3), 153-160. doi: 10.1016/j.jpag.2011.01.001

Sangalang, B. B., Barth, R. P., \& Painter, J. S. (2006). First-birth outcomes and timing of second births: A statewide case management program for adolescent mothers. Health and Social Work, 31(1), 54-64. doi:10.1093/hsw/31.1.54 
Santelli J., Ott, M. A., Lyon, M., Rogers, J., Summers, D., \& Schleifer, R. (2006). Abstinence and abstinence-only education: A review of U. S. policies and programs. Journal of Adolescent Health, 38, 72-81. doi:10.1016/j.jadohealth.2005.10.006

Schaffer, M. A., Jost, R., Pederson, B. J., \& Lair, M. (2008). Pregnancy-free club: A strategy to prevent repeat adolescent pregnancy. Public Health Nursing, 25(4), 304-311. doi:10.1111/j.1525-1446.2008.00746.x

Scholes, D., LaCroix, A. Z., Ichikawa, L. E., Barlow, W. E., \& Ott, S. M. (2005). Change in bone mineral density among adolescent women using and discontinuing Depot Medroxyprogesterone Acetate contraception. Archives of Pediatric Adolescent Medicine, 159, 139-144. doi:10.1001/archpedi.159.2.139

Schreiber, C. A., Ratcliffe, S. J., \& Barnhart, K. T. (2010). A randomized controlled trial of the effect of advanced supply of emergency contraception in postpartum teens: A feasibility study. Contraception, 81, 435 - 440. doi:10.1016/j.contraception.2010.01.017

Sidebottom, A., Harrison, P. A., Amidon, D., \& Finnegan, K. (2008). The varied circumstances prompting requests for emergency contraception at school-based clinics. The Journal of School Health, 78(5), 258-263. doi:10.1111/j.17461561.2008.00298.x

Simon, J. B., Murphy, J., \& Smith, S. M. (2005). Understanding and fostering family resilience. The Family Journal, 13(4), 427-436. doi:10.1177/1066480705278724

Singer, M., \& Baer, H. (2007). Introducing medical anthropology: A discipline in action. Lanham, MD: AltaMira.

Smith. A. (2005). An inquiry into the nature and causes of the wealth of nations. In J. Manis (Ed.) Pennsylvania State University Electronic Classics Series. Retrieved from http://www.hn.psu.edu/faculty/jmanis/adamsmith.htm (Original work published 1776)

Spear, H. J. (2004). Personal narratives of adolescent mothers-to-be: Contraception, decision making, and future expectations. Public Health Nursing, 21(4), 338346. doi:10.1111/j.0737-1209.2004.21407.x

The National Campaign to Prevent Teen Pregnancy. (2011). The cost of teen childbearing. Retrieved from http://www.thenationalcampaign.org/costs/default.aspx 
Thomas, D. V., \& Looney, S. W. (2004). Effectiveness of a comprehensive psychoeducational intervention with pregnant and parenting adolescents: A pilot study. Journal of Child and Adolescent Psychiatric Nursing, 17(2), 66-77. doi:10.1111/j.1744-6171.2004.00066.x

Thurman, A. R., Hammond, N., Brown, H., \& Roddy, M. E. (2007). Preventing repeat teen pregnancy: Postpartum Depot Medroxyprogesterone Acetate, oral contraceptive pills, or the patch? Journal of Pediatric Adolescent Gynecology, 20, 61-65. doi:10.1016/j.jpag.2006.11.006

Tocce, K. M, Sheeder, J. L, \& Teal, S. B. (2012). Rapid repeat pregnancy in adolescents: Do immediate postpartum contraceptive implants make a difference? American Journal of Obstetrics and Gynecology, 206, 481.e1-7 doi: 10.1016/j.ajog.2012.04.015

Tolaymat, L. L., \& Kaunitz, A. M. (2009). Use of hormonal contraception in adolescents: Skeletal health issues. Current Opinions in Obstetrics and Gynecology, 21(5), 396 - 401. doi:10.1097/GCO.0b013e32832c9cc6

Treffers, P. E., Olukoya, A. A., Ferguson, B. J., \& Liljestrand, J. (2001). Care for adolescent pregnancy and childbirth. International Journal of Gynecology and Obstetrics, 75, 111-121. doi:10.1016/S0020-7292(01)00368-X

Tobey, J., Hillman, S. B., Anagurthi, C., \& Somers, C. L. (2011). Demographic differences in adolescents' sexual attitude and behaviors, parent communication about sex, and school sex education. Electronic Journal of Human Sexuality, 14, 1-12. Retrieved from http://www.ejhs.org/volume14/Sexual\%20attitudes.htm

United Nations Population Information Network. (2001). Guidelines on reproductive health. Retrieved from http://www.un.org/popin/unfpa/taskforce/guide/iatfreph.gdl.html

United Nations. (2012). The millennium development goals report, 2012. Retrieved from http://www.un.org/millenniumgoals/pdf/MDG\%20Report\%202012.pdf

Van Breda, A. D. (2001). Resilience Theory: A literature review. Retrieved from http://www.adrian.vanbreda.org/resilience/resilience2.pdf

Ventura, S. J., \& Hamilton, B. E. (2011). U.S. teenage birth rate resumes decline. National Center for Health Statistics Data Brief, No. 58. Retrieved from http://www.cdc.gov/nchs/data/databriefs/db58.htm

Wagnild, G. (2009). A review of the Resilience Scale. Journal of Nursing Measurement, 17, 105-113. doi:10.1891/1061-3749.17.2.105 
Wagnild, G. M., \& Young, H. M. (1993). Development and psychometric evaluation of the Resilience Scale. Journal of Nursing Measurement, 1(2), 165-178.

Walsh, F. (1996). Family resilience: A concept and its application. Family Process, 35 (3), 261-281. doi:10.1111/j.1545

Walsh, F. (2003). Family resilience: A framework for clinical practice. Family Process, 42(1), 1-18. doi:10.1111/j.1545-5300.2003.00001.x

Werner, E. E. (1992). The children of Kauai: Resiliency and recovery in adolescent and adulthood. Journal of Adolescent Health, 13(4), 262-268.

West, R. (2007). Book review: Social justice: The moral foundations of public health and health policy. DePaul Journal of Health Care Law, 10(2), 567-585.

Wilson, E. K., Samandari, G., Koo, H. P., \& Tucker, C. (2011). Adolescent mothers' postpartum contraceptive use: A qualitative study. Perspectives on Sexual and Reproductive Health, 43(4), 230-237. doi:10.1363/4323011

Windle, G., Bennett, K. M., \& Noyes, J. (2011). A methodological review of resilience measurement scales. Health and Quality of Life Outcomes, 9, 1-18. doi:10.1186/1477-7525-9-8

World Health Assembly. (2011). Youth and health risks. Retrieved from http://apps.who.int/gb/ebwha/pdf_files/WHA64/A64_R28-en.pdf

World Health Organization. (2009). Adolescent pregnancy. Retrieved from www.who.int/making_pregnancy_safer/topics/adoeslecnt_pregnancy/en/print.htm 1.

Youngkin, E. W. (2005). Adam Smith's moral and economic theory. Retrieved from http://www.quebecoislibre.org/05/050415-16.htm 


\section{APPENDIX 1}

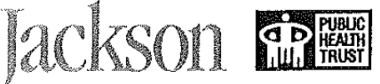 \\ MEMORIAL HOSPITAL \\ Jackson Health System}

1611 N.W. 12th Avenue

Minmi, Florida 33136-1094

October 24,2012

IRB Division of Research

Florida International University

11200 SW $8^{\text {th }}$ Street

Marc 430 Miami, FL 33199

RE: Letter of Support

To whom it may concern:

The Women's Hospital Center fully supports a planned research project to investigate the effects of resilience and social support on adolescent mothers' use of contraceptive, abstinence and a repeat adolescent pregnancy.

Teenage pregnancy is a major health concern with increased risk of maternal and fetal morbidity and mortality. Prematurity and increased length of hospital stay are among the significant health burdens for which teenagers are at highest risk.

Therefore, we are willing to share and support this research project.

Sincerely,

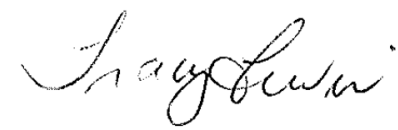

Tracy Lewis, RN, MSN, RNC-OB

Director Patient Care Services

Women's Hospital Center

Jackson Memorial Hospital

1611 NW 12 Ave Miami, FL 33136 


\section{Jackson South 照閳 COMMUNITY HOSPITAL \\ A Division of Jackson Memorial Hospital \\ Jackson Health System}

December 31,2012

IRB Division of Research

Florida International University

11200 SW $8^{\text {th }}$ Street

Miami, Florida 33199

RE: Letter of Support

To whom it may concern:

The Women's Center at Jackson South acknowledges the request from Nola Hòlness, CNM to participate in a research study to determine the effects of resilience and social influences on preventing a repeat adolescent pregnancy.

Adolescent pregnancy in the Unites States remains one of the highest among other industrialized countries. Also, childbearing by adolescents continues to be a matter of public concern due to the increased health risk to teen mothers and their infants.

Therefore, we are willing to support and participate in this research study.

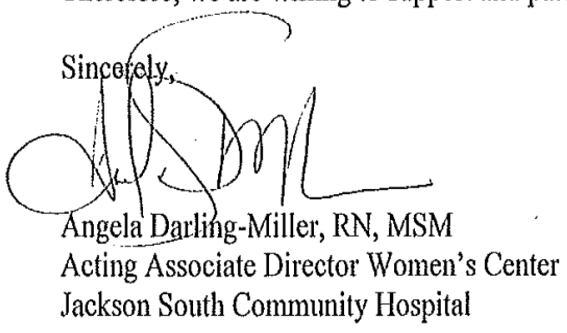

An Eq̨ull Opportunity limplogir 


\section{Jackson North \\ Miracles made daily. \\ Women's \& Children
160 NW $170^{\text {in }}$ Street
North Miami Beach, Florida 33169 \\ www.JacksonHeallh.org \\ 305-651-1100}

March 12013

IRB Division of Research, Marc 430

Florida International University

11200 SW $8^{\text {th }}$ Street

Miami, Florida, 33199

RE: Letter of Support

To whom it may concern:

Jackson North Maternity Department supports the research study on adolescent pregnancy being proposed by Nola Holness, Certified Nurse Midwife and PhD student at Florida International University.

The dilemma of adolescent pregnancy remains a major concern in the United States. Therefore we share in this project to determine the internal and external influences on a teen mother having a repeat adolescent pregnancy.

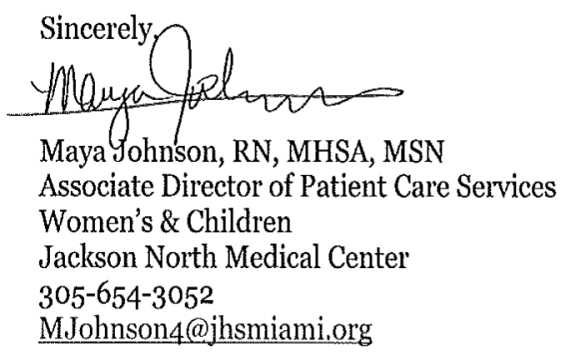


VITA

NOLA HOLNESS

Born, Kingston, Jamaica

1992-Present

$\mathrm{RN} / \mathrm{CNM}$

Jackson Memorial Hospital

Miami, Florida

1996

Nurse-Midwifery Precertification

Jackson Memorial Hospital

Miami, Florida

2000

BSN, Nursing

Florida International University

Miami, Florida

2008

MSN, Nursing

Florida International University

Miami, Florida

2010

Women's Hospital Advanced Practice Nurse of the Year

Jackson Memorial Hospital

Miami, Florida

2009-2014

Doctoral Candidate

Florida International University

Miami, Florida

\section{PUBLICATIONS AND PRESENTATIONS}

Holness, N. (2011). Coming home to Africa: An emic experience in Ghana. Reflections on Nursing Leadership, 37 (1).

Porter, L. \& Holness, N. (2011). Breaking the repeat teen pregnancy cycle: How nurses can nurture resilience in at-risk teens. Nursing for Women's Health, (15) 5, 369-381.

Holness, N. (2012). Global perspective on teen pregnancy. Abstract accepted for podium presentation at Pan American's XIII Nursing Research Colloquium. (Miami, Florida) 
Holness, N. (2013). Perceptions of patient, staff, and community on the role and function of Certified Nurse- Midwives. Program book of the American College of NurseMidwives $58^{\text {th }}$ Annual Meeting and Exhibition, 31. (Nashville, Tennessee).

Holness, N. (2012). Perceptions of patient, staff, and community on the role and function of Certified Nurse- Midwives. Program book of the Nursing Summit, the 30th Anniversary of Nursing at FIU, 20. (Miami, FL).

Holness, N. (2012). Panelist, 30 Nursing Ideas to Impact Nursing. Nursing Summit, 30th Anniversary of Nursing at FIU. (Miami, FL).

Holness, N. (2012). Perceptions of patient, staff, and community on the role and function of Certified Nurse Midwives. Conference proceedings of the 26th Annual Southern Nursing Research Conference. (New Orleans, LA).

Holness, N. (2011). The cost of adolescent pregnancy: Who pays and how much? Program book of the 5th Annual Nursing and Health Research Collaborative of South Florida. (Miami, FL).

Holness, N. (2011). The Dark Side of Adolescent Pregnancy: Shining a Light Within. Program book of the 6th Annual BHSF Research Conference. (Miami, FL). 